\title{
The Dynamic Multisensory Engram: Neural Circuitry Underlying Crossmodal Object Recognition in Rats Changes with the Nature of Object Experience
}

\author{
Derek L. Jacklin, ${ }^{\star}$ Jacob M. Cloke, ${ }^{\star}$ Alphonse Potvin, Inara Garrett, and Boyer D. Winters \\ Department of Psychology and Collaborative Neuroscience Program, University of Guelph, Ontario N1G 2W1, Canada
}

Rats, humans, and monkeys demonstrate robust crossmodal object recognition (CMOR), identifying objects across sensory modalities. We have shown that rats' performance of a spontaneous tactile-to-visual CMOR task requires functional integration of perirhinal (PRh) and posterior parietal (PPC) cortices, which seemingly provide visual and tactile object feature processing, respectively. However, research with primates has suggested that $\mathrm{PRh}$ is sufficient for multisensory object representation. We tested this hypothesis in rats using a modification of the CMOR task in which multimodal preexposure to the to-be-remembered objects significantly facilitates performance. In the original CMOR task, with no preexposure, reversible lesions of PRh or PPC produced patterns of impairment consistent with modality-specific contributions. Conversely, in the CMOR task with preexposure, PPC lesions had no effect, whereas PRh involvement was robust, proving necessary for phases of the task that did not require PRh activity when rats did not have preexposure; this pattern was supported by results from c-fos imaging. We suggest that multimodal preexposure alters the circuitry responsible for object recognition, in this case obviating the need for PPC contributions and expanding PRh involvement, consistent with the polymodal nature of PRh connections and results from primates indicating a key role for PRh in multisensory object representation. These findings have significant implications for our understanding of multisensory information processing, suggesting that the nature of an individual's past experience with an object strongly determines the brain circuitry involved in representing that object's multisensory features in memory.

Key words: c-fos; cross-modal; multisensory integration; parietal cortex; perirhinal cortex

\section{Significance Statement}

The ability to integrate information from multiple sensory modalities is crucial to the survival of organisms living in complex environments. Appropriate responses to behaviorally relevant objects are informed by integration of multisensory object features. We used crossmodal object recognition tasks in rats to study the neurobiological basis of multisensory object representation. When rats had no prior exposure to the to-be-remembered objects, the spontaneous ability to recognize objects across sensory modalities relied on functional interaction between multiple cortical regions. However, prior multisensory exploration of the task-relevant objects remapped cortical contributions, negating the involvement of one region and significantly expanding the role of another. This finding emphasizes the dynamic nature of cortical representation of objects in relation to past experience.

\section{Introduction}

Our capacity to perceive, recognize, and understand our environment relies on the integration of distinct sensory stimuli, which in

Received Aug. 12, 2015; revised Dec. 1, 2015; accepted Dec. 13, 2015.

Author contributions: D.L.J., J.M.C., and B.D.W. designed research; D.L.J., J.M.C., A.P., and I.G. performed research; D.L.J., J.M.C., A.P., I.G., and B.D.W. analyzed data; D.L.J., J.M.C., and B.D.W. wrote the paper.

This research was supported by a National Sciences and Engineering Research Council (NSERC) of Canada Discov-

ery Grant (B.D.W.), an Ontario Graduate Scholarship (D.L.J.), and an NSERC postgraduate scholarship (J.M.C.).

The authors declare no competing financial interests.

${ }^{*}$ D.L.J. and J.M.C. contributed equally to this work.

Correspondence should be addressed to Dr. Boyer D. Winters, Dept. of Psychology, University of Guelph, Guelph, 0N N1G 2W1 Canada. E-mail: bwinters@uoguelph.ca.

DOI:10.1523/JNEUROSCI.3043-15.2016

Copyright $\odot 2016$ the authors $\quad 0270-6474 / 16 / 361273-17 \$ 15.00 / 0$ turn enables us to direct appropriate behavioral responses to specific objects (Murray et al., 1998). Therefore, it is not surprising that learning of certain tasks can be improved when meaningfully related but sensorially distinct stimuli are presented together as cues (Shams and Seitz, 2008). Despite recent advances, it remains unclear whether this facilitation in learning after multimodal sensory training is the result of enhanced encoding and storage of information across multiple unimodal brain regions, a strengthening of connections between these unimodal regions, or the formation of a multisensory representation of the learning experience in a polymodal brain area (Amedi et al., 2005; Lacey et al., 2007).

To investigate the neural mechanisms of multisensory object representation, we previously developed a crossmodal object recognition (CMOR) task, in which rats are asked to recognize an 
object visually using a previously acquired tactile object representation. Performance on this spontaneous tactile-to-visual CMOR task requires functional interaction between the perirhinal (PRh) and posterior parietal (PPC) cortices. Our findings suggest that $\mathrm{PRh}$ is essential for analyzing visual aspects of object features, whereas the processing of tactile information depends on PPC and communication between these two regions is necessary to perform the CMOR task (Winters and Reid, 2010).

Although our previous CMOR results suggest a selective role for $\mathrm{PRh}$ in visual object processing, several lines of evidence indicate broader involvement of this brain area in object recognition (Málková et al., 1995; Buckley and Gaffan, 2006; Murray et al., 2007; Winters et al., 2008) and compelling findings from work with monkeys and humans implicate PRh in multisensory integration of object features (Murray et al., 1998; Goulet and Murray, 2001; Taylor et al., 2006; Holdstock et al., 2009; Taylor et al., 2009). Furthermore, the connectivity (Deacon et al., 1983; Suzuki and Amaral, 1994; Burwell and Amaral, 1998) and cytoarchitecture (Lavenex et al., 2004; Unal et al., 2012) of PRh seems to favor the amalgamation of sensory information from across several modalities into a unified multisensory construct.

We speculated that the limited role of PRh in our CMOR paradigm reflects the unique methodology of the task. As rats are required to explore the tactile and visual characteristics of objects in distinctly separate phases, they are never afforded the opportunity to associate these object properties together explicitly. We have therefore introduced a modified version of the CMOR task in which rats are given a brief multimodal preexposure session $24 \mathrm{~h}$ before undergoing CMOR (PE/CMOR; Reid et al., 2012, 2014). We hypothesized that allowing rats to experience simultaneously the tactile and visual properties of an object before testing alters the way the object is represented in the brain. Specifically, experiencing the object in a multimodal form might result in the tactile and visual characteristics of the object becoming associated within $\mathrm{PRh}$, creating a multisensory object representation capable of facilitating performance on the CMOR task. We reported previously that multimodal object preexposure does aid CMOR ability because rats can perform the task across significantly longer retention delays than when run without the preexposure or with simply unimodal (tactile only or visual only) preexposure sessions (Reid et al., 2012, 2014). In the current study, we first sought to probe the specific roles of PRh and PPC in the original CMOR task, evaluating their involvement with reversible lesions at various stages of CMOR performance. We then performed a similar analysis of the PE/CMOR task, predicting that, although PRh might be involved selectively in the visual choice phase of the original CMOR task, its temporal involvement would change after multimodal object preexposure, consistent with the hypothesis that a PRh-dependent multisensory object representation underlies the facilitative effects of the preexposure session. Results with reversible lesions, as well as cellular imaging with the protein product of the immediate early gene $c$-fos, supported this hypothesis.

\section{Materials and Methods}

Subjects. In total, this study used 176 adult male Long-Evans rats (Charles River Labs) weighing $\sim 300-350 \mathrm{~g}$ at the onset of each experiment. Rats were housed in pairs and were maintained during testing at $\sim 85 \%$ of their free feed body weight with 15-20 g of food per rat after completion of trials each day. All behavioral testing occurred during the dark phase of the reverse light/dark cycle (8:00 A.M. lights off; 8:00 P.M. lights on). Access to water was available ad libitum. All procedures adhered to the guidelines of the Canadian Council on Animal Care and were approved by the Animal Care Committee at the University of Guelph.
Surgery. For intracranial infusion experiments, all rats were implanted bilaterally with 22-gauge indwelling cannulas aimed at PRh or PPC. Before and throughout surgery, rats were deeply anesthetized with isofluorane inhalation anesthetic (Benson Medical Industries). Rats also received a subcutaneous injection of the analgesic meloxicam $(1 \mathrm{mg} / \mathrm{kg}$; Boehringer Ingelheim) and $0.9 \%$ physiological saline $(6 \mathrm{ml})$ before being secured in a stereotaxic frame (Kopf Instruments) with the incisor bar set to $-3.3 \mathrm{~mm}$. After incision of the scalp, the skull was exposed and holes were drilled above the target regions. Placement of the cannulas was determined according to the following coordinates, measured relative to the skull at bregma (Paxinos and Watson, 1998): for PRh, AP $-5.5 \mathrm{~mm}$, $\mathrm{ML} \pm 6.6 \mathrm{~mm}, \mathrm{DV}-7.0 \mathrm{~mm}$; for PPC, AP $-4.3 \mathrm{~mm}$, ML $\pm 2.5 \mathrm{~mm}$, DV $-1.5 \mathrm{~mm}$. The cannulas were lowered into place and secured using four jeweler's screws and dental acrylic. Dummy cannulas with an outer diameter of $0.36 \mathrm{~mm}$ were cut to extend 1.1 and $0 \mathrm{~mm}$ beyond the tip of the PRh and PPC guide cannulas, respectively. Dummy cannulas were inserted into the guides during the surgery, where they remained for the duration of the experiment, only being temporarily removed for the infusion procedure. Upon completion of the surgery, the skin was sutured and rats were placed in a separate cage on heating pads for $1-2 \mathrm{~h}$ before being returned to their home cages, where they were allowed to recover for $7 \mathrm{~d}$.

Infusion procedure. Rats in the intracranial infusion experiments received bilateral infusions of either $0.9 \%$ physiological saline or $2 \%$ lidocaine (Sigma-Aldrich) into PRh (Experiments 1-3) or PPC (Experiments 4 and 5) immediately before preexposure (Experiments $2 \mathrm{a}$ and $5 \mathrm{a}$ ), after preexposure (Experiments $2 \mathrm{~b}$ and $5 \mathrm{~b}$ ), before the sample phase (Experiment $1 \mathrm{a}, 2 \mathrm{c}, 3,4 \mathrm{a}$, and $5 \mathrm{c}$ ), or before the choice phase (Experiment $1 \mathrm{~b}$, $2 \mathrm{~d}, 4 \mathrm{~b}$, and $5 \mathrm{~d}$ ). All infusions were performed in a separate room from the testing area with rats being gently restrained throughout the duration of the procedure. To begin, dummy cannulas were removed and 28-gauge infusion cannulas designed to project $1.0 \mathrm{~mm}$ and $0.5 \mathrm{~mm}$ beyond the tip of the guide for PRh and PPC, respectively, were inserted. A Harvard Apparatus precision syringe pump was used to deliver $0.5 \mu$ l to each hemisphere simultaneously through $21 \mu \mathrm{l}$ Hamilton syringes connected to the infusers with propylene tubing. The infusion lasted $1 \mathrm{~min}$ and infusers were left in place for an additional $1.5 \mathrm{~min}$ to allow diffusion of the infusate, after which the infusers were removed and the dummy cannulas were reinserted. This procedure has been shown previously to produce drug diffusion patterns predominately restricted to PRh with minimal, if any, spread into adjacent hippocampal or cortical structures (Winters and Bussey, 2005). After the infusion, rats were either returned to their home cages (Experiments $2 \mathrm{~b}$ and $5 \mathrm{~b}$ ) or tested on the appropriate test phase in the Y-apparatus (see below for specific experimental details).

Apparatus. The Y-shaped apparatus was used for all behavioral testing and has been described previously (Winters et al., 2004; Forwood et al., 2005). Briefly, the Y-apparatus consisted of three arms of equal size (40 $\mathrm{cm}$ high, $27 \mathrm{~cm}$ long, and $10 \mathrm{~cm}$ wide) constructed from solid white Plexiglas to prevent the rat from looking out into the room. One arm was designated as the start arm and contained a guillotine door $18 \mathrm{~cm}$ from the rear of the arm to confine the rats at the start of a given trial. The remaining 2 choice arms were equipped with notches $9 \mathrm{~cm}$ from the back of the arms to allow the insertion of transparent plastic barriers to prevent rats from gaining physical access to the objects. The objects used in the present study were triplicate copies made from plastic, ceramic, and glass. They ranged in height from 10 to $20 \mathrm{~cm}$ and varied with respect to their visual and tactile qualities (for some examples of object sets, see Reid et al., 2014). Objects were affixed to the floor of the apparatus with odorless, reusable adhesive putty. Objects were always wiped with $50 \%$ ethanol before being placed into the apparatus to control for any olfactory cues. Animals were exposed to new, never-before-seen objects on each trial. A JVC Everio digital camera was mounted on a tripod above the apparatus to record all trials.

Y-apparatus habituation. Each rat was allowed to explore the Y-apparatus for $5 \mathrm{~min}$ twice per day over $2 \mathrm{~d}$. Rats were acclimatized to both the tactile (red light) and visual (white light with 2 transparent plastic barriers) conditions equally in a counterbalanced fashion over the $2 \mathrm{~d}$. Objects were never present in the Y-apparatus during the habituation phase. In addition, before being placed into the apparatus, once per day, rats in the intracranial 
infusion experiments underwent the infusion procedure as described above, with injectors being lowered into place but no substance infused.

Intracranial infusion experiments: behavior. The CMOR task is a modified version of the spontaneous object recognition (SOR) task, relying on the innate tendency of rats to preferentially explore novel versus familiar objects (Ennaceur and Delacour, 1988; Winters and Reid, 2010). All intracranial experiments followed a similar procedure in which rats were transferred from the colony room to the testing room and placed in the start arm. The guillotine door was raised and the session began as the rat exited the start arm. In addition, all experiments consisted of a sample phase and a choice phase separated by a retention delay ( 1 or $3 \mathrm{~h}$; see specific experimental details below). In the sample phase, two identical objects were placed at the back of the choice arms. This phase lasted either $3 \mathrm{~min}$ or until the rat had accumulated $25 \mathrm{~s}$ of object exploration, which was defined as directing the nose toward a part of the object or an area of the transparent barrier that the object was situated behind (visualonly conditions) at a distance of $<2 \mathrm{~cm}$. Upon completion of the sample phase, rats were returned to the colony room in their home cage for the duration of the retention delay. For the choice phase, an identical version of the object from the sample phase and a novel object were presented in the choice arms. The side on which the novel object was placed was randomized across subjects and trials. This phase was recorded for $1 \mathrm{~min}$.

In Experiments 1 and 4, novel object preference was assessed after presample (Experiments 1a and 4a) or prechoice (Experiments $1 \mathrm{~b}$ and $4 \mathrm{~b}$ ) infusions of saline or lidocaine on tactile and visual SOR and CMOR tasks. For these experiments, the retention delay between sample and choice phases was the typical $1 \mathrm{~h}$ (Winters and Reid, 2010). For the tactile SOR task, both the sample and choice phases were conducted with the apparatus illuminated only with red light from a lamp mounted on the camcorder tripod above the $\mathrm{Y}$-apparatus. This effectively prevented rats from acquiring visual information about the objects because rats have poor spectral sensitivity for acute vision in red light (Jacobs et al., 2001; Winters and Reid, 2010). For the visual SOR task, rats were prevented from acquiring any tactile information about the objects during the sample and choice phases by a transparent plastic barrier inserted in the choice arms between the rats and the objects. The overhead white lights were illuminated, allowing vision of the objects during this task. For the CMOR task, the sample phase was run in red light (tactile) and the choice phase was run in white light with the transparent barriers in place (visual). Each rat received both drugs on all three tasks in a counterbalanced order for a total of six trials per rat. Each trial was run with a unique set of objects for each rat.

In Experiments 2, 3, and 5, rats were simultaneously preexposed to the tactile and visual features of the to-be-remembered objects $24 \mathrm{~h}$ before the tactile sample phase of the CMOR task (PE/CMOR); this preexposure phase took place in the same $\mathrm{Y}$-apparatus as all other testing phases. In this task, rats receiving saline or lidocaine were run on two conditions in a counterbalanced order for a total of four trials per rat. In one trial, animals received a preexposure phase consisting of a brief multimodal exposure to the sample objects $24 \mathrm{~h}$ before the tactile sample phase. This session was conducted with the white lights on and full access given to the tactile features of the objects for either $10 \mathrm{~s}$ of object exploration or until $2 \mathrm{~min}$ had elapsed. In another condition ("no preexposure"), the preexposure phase was omitted and rats remained in their home cage. We have shown previously that rats not receiving multimodal object preexposure are unable to perform CMOR at retention delays of $3 \mathrm{~h}$, whereas allowing rats to experience the tactile and visual properties of an object simultaneously facilitates CMOR across retention delays of up to $24 \mathrm{~h}$ (Reid et al., 2012). Moreover, we have reported previously that the preexposure session must be multimodal in nature (i.e., tactile only or visual only preexposure does not result in facilitation with delays longer than $1 \mathrm{~h}$ ) and that evidence suggests that the multimodal preexposure session does not merely serve as a sample phase (i.e., when the tactile sample phase is omitted from the PE/CMOR procedure described above, animals fail to discriminate between the objects in the choice phase; Reid et al., 2012, 2014). Therefore, we evaluated CMOR performance of rats receiving infusions of saline or lidocaine before (Experiments $2 \mathrm{a}$ and $5 \mathrm{a}$ ) or after preexposure (Experiments $2 \mathrm{~b}$ and $5 \mathrm{~b}$ ) or before the sample (Experiments $2 \mathrm{c}, 3$, and $5 \mathrm{c}$ ) or choice phases (Experiments $2 \mathrm{~d}$ and $5 \mathrm{~d}$ ) of the PE/CMOR task with a $3 \mathrm{~h}$ retention delay (Experiments 2 and 5). We predicted that, if a particular manipulation interfered with the storage or utilization of a multisensory representation, performance would resemble that of rats not given multimodal preexposure. Finally, for comparison purposes and to control for the potential retention delay confound between the typical CMOR and PE/CMOR tasks, Experiment 3 was run with PE/CMOR but with a $1 \mathrm{~h}$ retention delay. Figure 1 illustrates the various procedures used for the intracranial infusion experiments (Experiments 1-5) and Table 1 summarizes details from all experiments, including primary results.

Histology. After completion of intracranial behavioral testing, rats were anesthetized by intraperitoneal injection of $1.5 \mathrm{ml}$ of Euthansol ( 85 $\mathrm{mg} / \mathrm{ml}$; Schering) and perfused transcardially with $100 \mathrm{ml}$ of PBS, $\mathrm{pH} 7.4$, followed by $250 \mathrm{ml}$ of $4 \%$ neutral buffered formalin, $\mathrm{pH}$ 7.4. Brains were then extracted and postfixed in $4 \%$ formalin at $4^{\circ} \mathrm{C}$ for at least $24 \mathrm{~h}$ before being immersed in $20 \%$ sucrose in PBS until they sank. Coronal sections $(50 \mu \mathrm{m})$ were sliced on a cryostat freezing microtome through the extent of PRh or PPC and every fifth section was mounted on a gelatin-coated glass slide and stained with thionin. Slides were examined under a light microscope to verify cannula placements.

c-fos behavioral testing. Two additional experiments were performed to explore the pattern of neuronal activity induced after multimodal preexposure to objects. In Experiment 6, rats were exposed to a session analogous to the multimodal preexposure session described above. An important difference, however, was that, for these experiments, rats were run through a total of 30 preexposure trials back to back to ensure robust expression of Fos protein. All rats were habituated to the Y-apparatus as described above $24 \mathrm{~h}$ before the preexposure session. Each preexposure trial consisted of duplicate copies of trial unique objects being presented in the exploration arms of the $\mathrm{Y}$-apparatus, resulting in each rat experiencing 30 novel objects in the course of $\sim 1 \mathrm{~h}$. The time required for rats in this group to complete $10 \mathrm{~s}$ of object exploration for each trial was recorded to ensure that there were no differences in exploration levels between conditions. The next trial did not begin until the rat had explored the current objects for $10 \mathrm{~s}$. Once $10 \mathrm{~s}$ of exploration had occurred, the rat was removed from the $\mathrm{Y}$-apparatus and placed back into the start box while new objects were inserted into the exploration arms. As soon as the objects were in place, the next trial was run. In a second group, each rat was matched with a rat from Group 1 and spent an equal amount of time exploring an empty Y-apparatus over the course of 30 trials to control for general activity effects during this period. Experiment 7 was designed to assess patterns of neuronal activation after tactile object exploration analogous to the tactile sample phase in the CMOR task. Rats were assigned to one of four groups: no preexposure/no sample, preexposure/no sample, no preexposure/sample, and preexposure/sample. Rats in the preexposure/no sample and preexposure/sample groups received multimodal preexposure to objects as described for Experiment 6 . The remaining two groups spent an equal amount of time in the empty Y-apparatus. Twenty-four hours after the preexposure phase, the tactile sample phase began. Rats in the preexposure/sample and no preexposure/sample groups were exposed to the tactile features (i.e., in red light) of the same 30 objects explored by the preexposure/sample group in the preexposure phase; each sample phase ended when the rat had explored the objects for a total of $25 \mathrm{~s}$ or when $3 \mathrm{~min}$ had elapsed. For the no preexposure/sample group, this was the first exposure to these objects in any context. Rats in the no preexposure/no sample and preexposure/no sample groups spent an equal amount of time exploring the empty $\mathrm{Y}$-apparatus in the red light. Table 1 summarizes procedural details and primary results from all experiments.

c-fos immunohistochemistry protocol. One hour after rats completed the preexposure phase (Experiment 6) or the tactile sample phase (Experiment 7), they were anesthetized deeply with an intraperitoneal injection of $1.5 \mathrm{ml}$ of Euthansol $(85 \mathrm{mg} / \mathrm{ml})$ and perfused with $150 \mathrm{ml}$ of PBS, $\mathrm{pH} 7.4$, followed by $250 \mathrm{ml}$ of $4 \%$ fresh paraformaldehyde (PFA; $\mathrm{pH} 7.4$ ). Brains were removed and postfixed in $4 \%$ PFA for $24 \mathrm{~h}$ at $4^{\circ} \mathrm{C}$ before immersion in $30 \%$ sucrose for $48 \mathrm{~h}$. Coronal sections $(40 \mu \mathrm{m})$ were cut using a microtome through the entire brain with every fourth slice being used in the immunohistochemistry procedure. Immunostaining for Fos protein was performed on free-floating sections using a rabbit anti-Fos 
polyclonal antibody (Ab-5; Oncogene Science) diluted to $1: 100,000$ with a solution of $0.3 \%$ Triton X-100 in Tris-buffered saline (TBS) with $3 \%$ normal goat serum. The sections were incubated with the anti-Fos antibody for $48 \mathrm{~h}$ at $4^{\circ} \mathrm{C}$ and then rinsed in TBS and transferred to a solution of $0.3 \%$ Triton X-100 in TBS containing biotinylated anti-rabbit secondary antibody (1:200; Vector Laboratories) for $1 \mathrm{~h}$ at $4^{\circ} \mathrm{C}$. The sections were then rinsed and processed with avidin biotinylated horseradish peroxidase complex (Elite kit; Vector Laboratories) for $2 \mathrm{~h}$ at $4^{\circ} \mathrm{C}$. Fos immunoreactivity was detected using a nickel chloride enhanced diaminobenzidine reaction (DAB Substrate Kit; Vector Laboratories). Sections were then mounted on gelatin-coated glass slides, dehydrated through a series of alcohols, and coverslipped.

Data analysis. Object recognition was defined using the discrimination ratio as follows: (novel object exploration - familiar object exploration)/(novel object exploration + familiar object exploration) from the choice phase. For CMOR experiments, 2 (drug) $\times 3$ (task: CMOR, tactile SOR, visual SOR) repeatedmeasures ANOVAs were used to assess novel object preference. In addition, planned comparisons with paired-samples $t$ tests were used to contrast the effects of saline and lidocaine at each level of task. For PE/CMOR experiments, the discrimination ratio data were analyzed using 2 (drug) $\times 2$ (preexposure condition) repeated-measures ANOVAs. Planned comparisons were performed with paired-samples $t$ tests to compare saline with lidocaine administration at each level of the preexposure condition. One-sample $t$ tests comparing group means with 0 (chance analysis, i.e., no object preference) were also used as an additional assessment of object recognition. Three additional measures of exploratory behavior were analyzed using repeated-measures ANOVAs to ensure that there were no differences for general exploration of objects across drug conditions: total choice object exploration, total sample object exploration, and sample phase duration (i.e., the time required for rats to explore the sample objects for $25 \mathrm{~s}$ ). When appropriate, paired-samples $t$ tests were used to compare saline and lidocaine groups on object exploration and phase duration for the preexposure condition. Only significant effects are reported for these control measures. All statistical analyses were performed using SPSS 20 for Windows with a significance level of $\alpha=0.05$.

For c-fos analyses, digitized images of Fos immunoreactivity within PRh, PPC, and two control regions, primary auditory cortex (Aud) and motor cortex (M1 and M2), were obtained using a 10× objective and QCapture software (version 2.7.3; QImaging Corporation). Cell counting and area measurements were completed using ImageJ. Counts were conducted in all regions of interest from the right and left hemisphere for rectangular areas $(0.94 \times 0.67 \mathrm{~mm})$ throughout the anterior-posterior extent of the region of interest (Wan et al., 1999). The boundaries for measuring PRh counts were determined from those previously defined by Burwell (2001) and Wan et al. (1999). Counts within PRh were collected between $\sim 3.80$ and $7.16 \mathrm{~mm}$ posterior to bregma in both areas 35 and 36, which lie on the ventral and dorsal banks of the rhinal sulcus, respectively (Burwell, 2001). For topographic analyses of PRh, this region

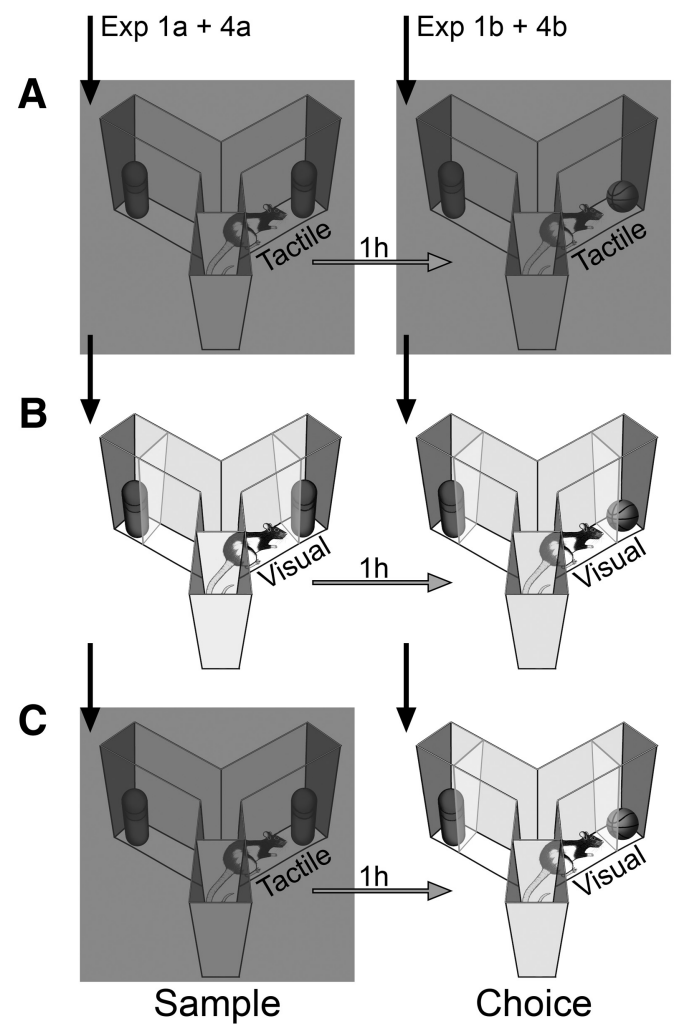

Figure 1. Schematic illustrating procedural details for PRh (Experiments 1-3) and PPC (Experiments 4 and 5) intracranial administration experiments. In Experiments 1a and 4a, lidocaine or saline was infused (downward arrows) directly into PRh or PPC, tasks. In Experiments $1 \mathrm{~b}$ and $4 \mathrm{~b}$, lidocaine or saline was infused into PRh or PPC, respectively, immediately before the choice phase 列 phase. There was a $24 \mathrm{~h}$ delay between preexposure and sample in all PE/CMOR experiments and a $3 \mathrm{~h}$ retention delay between sample and choice phases in Experiments 2 and 5 . Experiment 3 was identical to Experiment $2 c$, except that the retention delay between sample and choice was $1 \mathrm{~h}$.

of interest was divided into four approximately equal levels, corresponding to the following approximate coordinates posterior to bregma: $2.76-$ $3.24 \mathrm{~mm}$ (rostral), $3.60-4.08 \mathrm{~mm}$ (midrostral), 4.80-5.28 mm (midcaudal), and $6.48-6.96 \mathrm{~mm}$ (caudal). There were three sections analyzed per region, for a total of 12 sections for PRh analyses. Counts within PPC were performed between 3.60 and $4.08 \mathrm{~mm}$ posterior to bregma ( 3 sections). In primary auditory cortex, counts were made between 4.80 and $5.28 \mathrm{~mm}$ posterior to bregma ( 3 sections). For M1/M2, counts were collected at $\sim 2.76 \mathrm{~mm}$ posterior to bregma ( 1 section only). For statistical analyses of regional Fos expression, counts were first normalized according to matched pairs or groups of rats (e.g., preexposure vs empty for Experiment 6; all four conditions for Experiment 7; Albasser et al., 2010). This entailed dividing the mean number of Fos-positive 
Table 1. Summary of experimental details

\begin{tabular}{|c|c|c|}
\hline Experiment & Procedural summary & Primary finding \\
\hline 1a & $\begin{array}{l}\text { Pre-sample intra-PRh saline versus lidocaine; } \\
\text { CMOR, tactile, and visual SOR; } 1 \mathrm{~h} \\
\text { retention delay; } n=16\end{array}$ & $\begin{array}{l}\text { Lidocaine selectively impairs } \\
\text { visual SOR (Fig. } 3 A \text { ) }\end{array}$ \\
\hline $1 \mathrm{~b}$ & $\begin{array}{l}\text { Pre-choice intra-PRh saline versus lidocaine; } \\
\text { CMOR, tactile, and visual SOR; } 1 \mathrm{~h} \\
\text { retention delay; } n=12\end{array}$ & $\begin{array}{l}\text { Lidocaine impairs CMOR and } \\
\text { visual SOR (Fig. } 3 B \text { ) }\end{array}$ \\
\hline $2 a$ & $\begin{array}{l}\text { Pre-PE intra-PRh saline versus lidocaine; } \\
\text { PE/CMOR, PE versus no PE; } 3 \text { h retention } \\
\text { delay; } n=13\end{array}$ & $\begin{array}{l}\text { Lidocaine reverses facilitative } \\
\text { effect of multimodal } \\
\text { pre-exposure (Fig. } 4 A \text { ) }\end{array}$ \\
\hline $2 b$ & $\begin{array}{l}\text { Post-PE intra-PRh saline versus lidocaine; } \\
\text { PE/CMOR, PE versus no PE; } 3 \text { h retention } \\
\text { delay; } n=12\end{array}$ & $\begin{array}{l}\text { Lidocaine reverses facilitative } \\
\text { effect of multimodal } \\
\text { pre-exposure (Fig. } 4 B \text { ) }\end{array}$ \\
\hline $2 c$ & $\begin{array}{l}\text { Pre-sample intra-PRh saline versus lidocaine; } \\
\text { PE/CMOR, PE versus no PE; } 3 \text { h retention } \\
\text { delay; } n=9\end{array}$ & $\begin{array}{l}\text { Lidocaine reverses facilitative } \\
\text { effect of multimodal } \\
\text { pre-exposure (Fig. } 4 C \text { ) }\end{array}$ \\
\hline $2 d$ & $\begin{array}{l}\text { Pre-choice intra-PRh saline versus lidocaine; } \\
\text { PE/CMOR, PE versus no PE; } 3 \text { h retention } \\
\text { delay; } n=12\end{array}$ & $\begin{array}{l}\text { Lidocaine reverses facilitative } \\
\text { effect of multimodal } \\
\text { pre-exposure (Fig. 4D) }\end{array}$ \\
\hline 3 & $\begin{array}{l}\text { Pre-sample intra-PRh saline versus lidocaine; } \\
\text { PE/CMOR, PE versus no PE; } 1 \text { h retention } \\
\text { delay; } n=10\end{array}$ & $\begin{array}{l}\text { Lidocaine impairs performance } \\
\text { only when rats have } \\
\text { received multimodal } \\
\text { pre-exposure (Fig. 5) }\end{array}$ \\
\hline $4 a$ & $\begin{array}{l}\text { Pre-sample intra-PPC saline versus lidocaine; } \\
\text { CMOR, tactile, and visual SOR; } 1 \mathrm{~h} \\
\text { retention delay; } n=12\end{array}$ & $\begin{array}{l}\text { Lidocaine impairs CMOR and } \\
\text { tactile SOR (Fig. } 6 \mathrm{~A})\end{array}$ \\
\hline $4 b$ & $\begin{array}{l}\text { Pre-choice intra-PPC saline versus lidocaine; } \\
\text { CMOR, tactile, and visual SOR; } 1 \mathrm{~h}\end{array}$ & $\begin{array}{l}\text { Lidocaine impairs CMOR and } \\
\text { tactile SOR (Fig. 6B) }\end{array}$ \\
\hline
\end{tabular}

5a Pre-PE intra-PPC saline versus lidocaine; $\mathrm{PE} / \mathrm{CMOR}$, $\mathrm{PE}$ versus no $\mathrm{PE} ; 3 \mathrm{~h}$ retention delay $; n=11$

$5 \mathrm{~b} \quad$ Post-PE intra-PPC saline versus lidocaine; $\mathrm{PE} / \mathrm{CMOR}$, PE versus no PE; 3 h retention delay $n=9$

$5 c$

Pre-sample intra-PPC saline versus lidocaine; No effect of lidocaine (Fig. 7C) $P E / C M O R, P E$ versus no $P E ; 3$ h retention delay; $n=11$

$5 d$

Pre-choice intra-PPC saline versus lidocaine; $P E / C M O R$, PE versus no $P E ; 3$ retention delay; $n=7$

6 Rats exposed to 30 novel objects or yoked in empty Y-apparatus; simultaneous visual and tactile exploration possible; sacrifice 1 $\mathrm{h}$ later; brains processed for Fos expression; $n=16$ ( 8 per condition)

7 Rats given multimodal exposure to 30 novel objects or yoked in empty Y-apparatus, followed by tactile exposure to same 30 objects or empty Y-apparatus $24 \mathrm{~h}$ later; sacrifice $1 \mathrm{~h}$ after second phase; brains processed for Fos expression; $n=16$ (4 per condition)

No effect of lidocaine (Fig. 7A)

No effect of lidocaine (Fig. 7B)

No effect of lidocaine (Fig. 7D)

Multimodal object exposure significantly increases Fos expression in PRh

(Fig. 8\& 9)

\section{Multimodal 'pre-exposure'} followed by tactile 'sample' significantly increases Fos expression throughout PRh (Fig. 10)

Order of experiments and number $(n)$ of rats per experiment are shown. Different cohorts of rats were used for each experiment. Lidocaine experiments were within subject. PRh, perirhinal cortex; CMOR, crossmodal object recognition; SOR, spontaneous object recognition; PPC, posterior parietal cortex; PE, pre-exposure. Each yoked rat in Fos experiments spent the same amount of time in the empty $Y$-apparatus as a matched experimental rat that explored objects.

neurons in a specific brain region for a given rat by the combined mean of the rats in each matched pair (Experiment 6) or group of four (Experiment 7) and presenting this result as a percentage. Accordingly, all normalized scores across conditions in each experiment sum to 100. For Experiment 6, mean normalized counts of Fos-positive neurons were submitted to a two-way ANOVA with repeated measures with region of interest (PRh, PPC, Aud, and M1/M2) as a within-subjects factor and testing condition (object preexposure or empty Y-apparatus control) as a between-subjects factor. Independent samples $t$ tests comparing control and preexposure conditions for each region of interest were used to explore a significant interaction. As further assessment of potential topographic differences in PRh Fos expression, a three-way ANOVA with repeated measures [testing condition $\times \mathrm{PRh}$ area $(35 / 36) \times$ rostralcaudal level] was run. For Experiment 7, mean normalized Fos counts from $\mathrm{PRh}$ of rats in each treatment condition were analyzed using a three-way ANOVA with these same factors. Post hoc tests were run with independent-samples $t$ tests.

\section{Results \\ Histology}

Animals included in Experiments 1, 2, and 3 with guide cannulas aimed toward $\mathrm{PRh}$ were consistently found to have bilateral infuser tips terminating near the border of area 35 and 36 between 5.80 and $6.12 \mathrm{~mm}$ posterior to bregma (Fig. $2 \mathrm{~A}, B$ ). All rats tested in Experiments 4 and 5 were found to have bilateral infuser tips terminating in PPC between 3.24 and $3.84 \mathrm{~mm}$ posterior to bregma (Fig. 2C,D).

\section{Experiment 1: bilateral inactivation of PRh in CMOR and unimodal SOR tasks}

To evaluate the temporal role of the PRh in CMOR, rats with bilateral cannulas aimed at $\mathrm{PRh}$ received infusions of saline or lidocaine immediately before sample or choice phases of the CMOR and unimodal (tactile only and visual only) SOR tasks. The retention delay was $1 \mathrm{~h}$ for these experiments.

\section{Experiment 1a: presample inactivation of PRh in CMOR}

Transient inactivation of PRh before the sample phase resulted in object recognition impairments on the visual SOR task only. Repeated-measures ANOVA revealed nonsignificant main effects of task $\left(F_{(2,30)}=1.645, p=0.210\right)$ and $\operatorname{drug}\left(F_{(1,15)}=0.398\right.$, $p=0.538)$, but a significant task $\times$ drug interaction $\left(F_{(2,30)}=\right.$ $3.515, p=0.043)$. Planned-comparison $t$ tests comparing saline with lidocaine (based on our previous lesion effects; Winters and Reid, 2010) indicated a significant impairment in the lidocaine condition on visual SOR $\left(t_{(15)}=2.344, p=0.033\right)$, but not $\operatorname{CMOR}\left(t_{(15)}=-0.854, p=0.406\right)$ trials (Fig. 3A). Furthermore, separate one-sample $t$ tests comparing discrimination ratios with zero indicated significant novel object preference in all conditions (visual: saline, $t_{(15)}=5.704, p<0.001$; tactile: saline, $t_{(15)}=$ 3.064, $p=0.008$; lidocaine, $t_{(15)}=4.929, p<0.001$; crossmodal: saline, $t_{(15)}=5.827, p<0.001$; lidocaine, $t_{(15)}=3.701, p=$ $0.002)$, except when rats were tested on visual SOR after infusions of lidocaine $\left(t_{(15)}=0.997, p=0.334\right)$. As reported previously (Winters and Reid, 2010; Reid et al., 2012), analyses of the general exploration data for sample and choice object exploration, as well as sample phase duration, revealed a significant main effect of task. This effect is attributed to the different stimulus properties present during each task because rats typically explore more when the tactile properties are available. Importantly, there were no drug or drug $\times$ task interaction effects. These results were consistent throughout all CMOR experiments in the present study (for all general exploratory control data from Experiments 1-5, see Tables 2, 3, 4).

\section{Experiment 1b: prechoice inactivation of PRh on CMOR}

Lidocaine administered to PRh before the choice phase produced object recognition impairments in both the visual SOR and $\mathrm{CMOR}$ tasks. Analysis of the discrimination ratios with repeatedmeasures ANOVA revealed significant main effects of task 
A

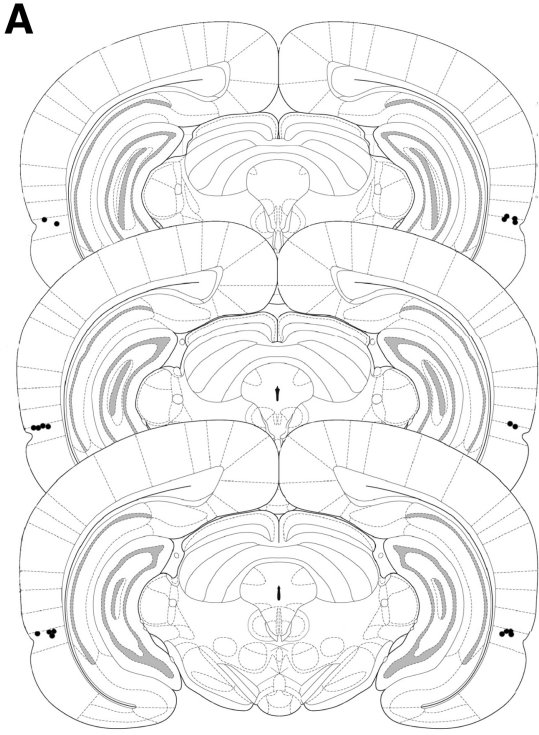

C

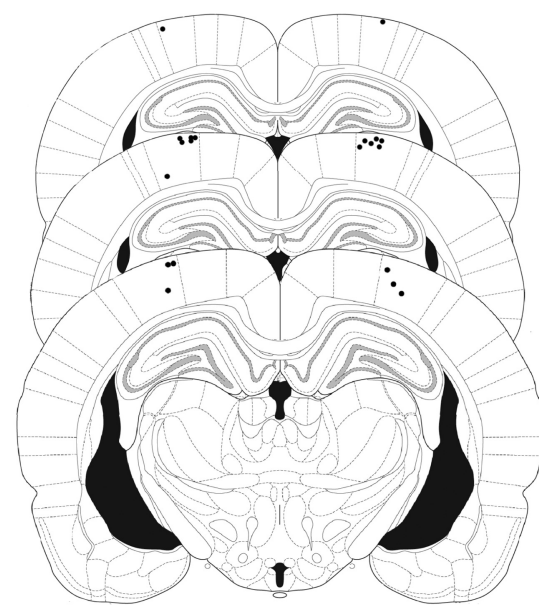

B

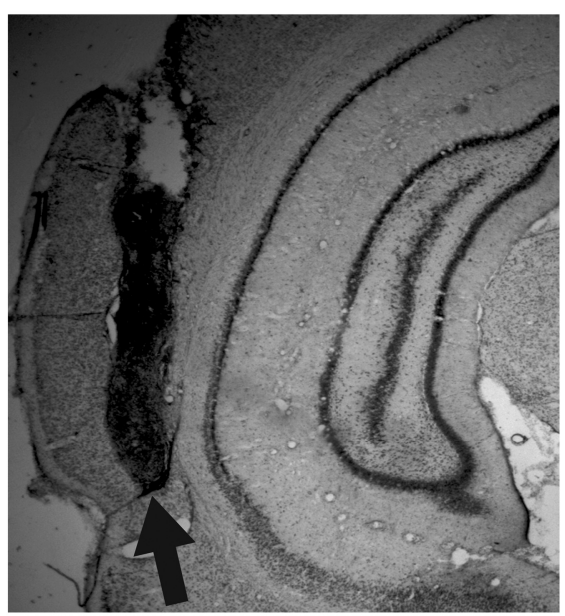

Bregma - $3.24 \mathrm{~mm}$

Bregma - $3.36 \mathrm{~mm}$

Bregma - $3.84 \mathrm{~mm}$

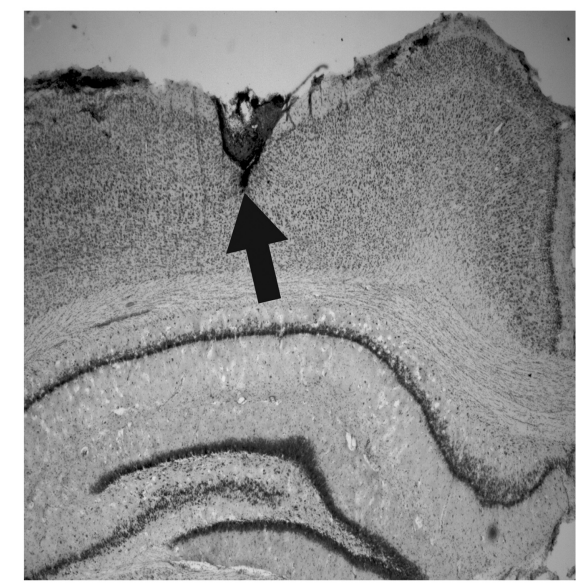

Figure 2. Cannula placements in PRh and PPC. A, Placements of infusion cannula tips in PRh from rats in a representative experiment (Experiment $2 b ; n=12$ ). All rats included in behavioral analyses had cannulas located between 5.88 and $6.12 \mathrm{~mm}$ posterior to bregma and near the border between areas 35 and 36 . B. Microphotograph (1.5× magnification) showing a guide cannula tract in the left hemisphere of a rat from Experiment $2 \mathrm{~b}$; the arrow indicates the infusion cannula tip. $C$, Placements of infusion cannula tips in PPC from rats in a representative experiment (Experiment $4 \mathrm{a} ; n=12)$. All rats included in behavioral analyses had cannulas located between 3.24 and $3.84 \mathrm{~mm}$ posterior to bregma. $\boldsymbol{D}$, Microphotograph $(1.5 \times$ magnification) showing a guide cannula tract in the left hemisphere of a rat from Experiment 4a; the arrow denotes the infusion cannula tip.

$\left(F_{(2,22)}=21.231, p<0.001\right)$ and drug $\left(F_{(1,11)}=27.411, p<\right.$ $0.001)$, but a nonsignificant task $\times$ drug interaction term $\left(F_{(2,22)}\right.$ $=1.681, p=0.209)$. Planned comparisons with paired-samples $t$ tests revealed that lidocaine infused into PRh significantly impaired object recognition on the visual SOR $\left(t_{(11)}=2.615, p=\right.$ $0.024)$ and $\operatorname{CMOR}\left(t_{(11)}=3.792, p=0.003\right)$ tasks (Fig. $3 B$ ). Moreover, this pattern of effects was supported with separate one-sample $t$ tests demonstrating significant novel object preference in all conditions (visual: saline, $t_{(11)}=2.954, p=0.013$; tactile: saline, $t_{(11)}=10.188, p<0.001$; lidocaine, $t_{(11)}=7.900$, $p<0.001$; crossmodal: saline, $\left.t_{(11)}=3.406, p=0.006\right)$, except in rats performing visual SOR $\left(t_{(11)}=-0.972, p=0.352\right)$ and $\operatorname{CMOR}\left(t_{(11)}=0.513, p=0.618\right)$ after infusions of lidocaine.

Experiment 2: bilateral inactivation of PRh in PE/CMOR task The results from Experiment 1 are consistent with findings from our previous study using neurotoxic lesions (Winters and Reid, 2010) and further implicate PRh as an important brain region for processing visual object information necessary for CMOR when animals have had no prior experience with the to-be-remembered objects. To assess the involvement of $\mathrm{PRh}$ in CMOR after preexposure to the combined tactile and visual properties of the sample object, rats with bilateral cannulas directed toward $\mathrm{PRh}$ received infusions of saline or lidocaine immediately before or after the preexposure phase or before the sample or choice phases of the PE/CMOR task. For Experiments $2 \mathrm{a}$-d, the retention delay was $3 \mathrm{~h}$, which prevents successful CMOR performance in the absence of multimodal preexposure (Reid et al., 2012, 2014).

\section{Experiment 2a: inactivation of PRh before the preexposure phase of PE/CMOR}

Reversible lesions of PRh before multimodal preexposure abolished the facilitative effects this phase confers on CMOR. Analysis of the repeated-measures ANOVA revealed significant main effects of preexposure $\left(F_{(1,12)}=22.997, p<0.001\right)$ and drug 
A PRh Pre-Sample

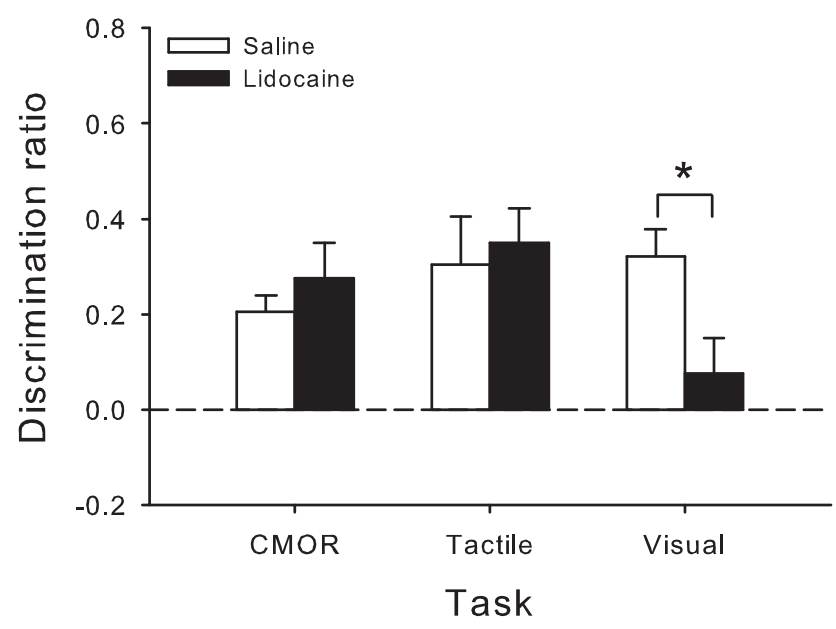

B

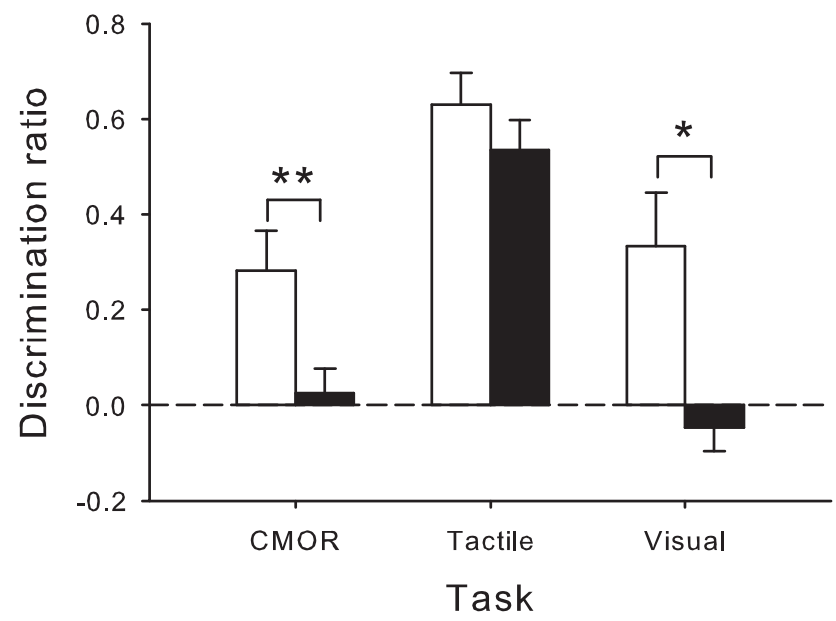

Figure 3. Object recognition performance of rats administered saline or lidocaine into PRh immediately before the sample phase of the CMOR, tactile, and visual SOR tasks $(n=16 ; \boldsymbol{A})$ or immediately before the choice phase of the CMOR, tactile, and visual SOR tasks $(n=12 ; \boldsymbol{B})$. Retention delay in all conditions was $1 \mathrm{~h}$. Data are presented as the average discrimination ratio ( \pm SEM). ${ }^{*} p<0.05 ;{ }^{* *} p<0.01$, saline versus lidocaine.

$\left(F_{(1,12)}=6.076, p=0.030\right)$, as well as a significant preexposure $\times$ drug interaction $\left(F_{(1,12)}=5.779, p=0.033\right)$. Post hoc analysis with paired-samples $t$ tests indicated a significantly higher discrimination ratio for saline compared with lidocaine trials in the preexposure condition $\left(t_{(12)}=2.788, p=0.016\right)$, but not the no preexposure condition $\left(t_{(12)}=-0.729, p=0.480\right.$; Fig. $\left.4 A\right)$. This pattern of effects was consistent with separate one-sample $t$ tests, which indicated a significant preference for the novel object in the preexposure condition when rats received infusions of saline $\left(t_{(12)}=4.552, p=0.001\right)$, but not in any other condition (no preexposure: saline, $t_{(12)}=-1.458, p=0.171$; lidocaine, $t_{(12)}=-0.825, p=0.425$; preexposure: lidocaine, $t_{(12)}=-0.214$, $p=0.834)$. General exploration analyses indicated a surprising preexposure $X$ drug interaction term for object exploration during the sample phase $\left(F_{(1,12)}=7.307, p=0.019\right)$. However, this result is unlikely to account for the impaired novel object preference during the choice phase, as post hoc analyses indicated that lidocaine rats in the preexposure condition actually spent more time exploring the objects during the sample phase compared with when they were treated with saline $\left(t_{(12)}=-2.255, p=\right.$
Table 2. Control measures collected from the preexposure phase for each condition from Experiments 2, 3, and 5

\begin{tabular}{lllc}
\hline Experiment & Drug condition & Total object exploration & Total phase duration \\
\hline 2a & Saline & $9.28 \pm 0.38$ & $74.40 \pm 11.89$ \\
& Lidocaine & $9.97 \pm 0.08$ & $74.30 \pm 8.68$ \\
2b & Saline & $9.56 \pm 0.49$ & $60.49 \pm 8.82$ \\
& Lidocaine & $9.28 \pm 0.49$ & $62.92 \pm 10.44$ \\
2c & Saline & $9.78 \pm 0.16$ & $83.34 \pm 9.12$ \\
& Lidocaine & $9.68 \pm 0.26$ & $60.03 \pm 8.03$ \\
2d & Saline & $7.94 \pm 0.47$ & $105.34 \pm 6.62$ \\
& Lidocaine & $7.44 \pm 0.35$ & $108.69 \pm 5.27$ \\
3 & Saline & 10 & $56.29 \pm 8.17$ \\
& Lidocaine & $9.99 \pm 0.07$ & $41.22 \pm 5.13$ \\
5a & Saline & $6.47 \pm 0.77$ & $100.98 \pm 7.22$ \\
& Lidocaine & $6.53 \pm 0.54$ & $101.53 \pm 7.45$ \\
5b & Saline & $8.14 \pm 0.41$ & $110.05 \pm 5.12$ \\
& Lidocaine & $8.21 \pm 0.42$ & $103.62 \pm 7.61$ \\
5c & Saline & $7.74 \pm 0.78$ & $96.02 \pm 10.11$ \\
& Lidocaine & $8.13 \pm 0.68$ & $87.23 \pm 11.70$ \\
5d & Saline & $8.95 \pm 0.74$ & $84.46 \pm 12.20$ \\
& Lidocaine & $8.93 \pm 0.65$ & $82.27 \pm 8.47$ \\
\hline
\end{tabular}

Data are expressed as the mean \pm SEM of the total time in seconds spent exploring the objects and the total duration of the preexposure phase in seconds.

0.044 ; see Table 3$)$. There was no such difference in the no preexposure condition $\left(t_{(12)}=1.698, p=0.115\right)$.

\section{Experiment 2b: inactivation of $\mathrm{PRh}$ after the preexposure phase of PE/CMOR}

Infusions of lidocaine into PRh immediately after the multimodal preexposure phase impaired CMOR performance at the $3 \mathrm{~h}$ retention delay. Repeated-measures ANOVA indicated significant main effects of preexposure $\left(F_{(1,11)}=5.704, p=0.036\right)$ and $\operatorname{drug}\left(F_{(1,11)}=17.331, p=0.002\right)$, but a nonsignificant drug $\times$ preexposure interaction $\left(F_{(1,11)}=2.856, p=0.119\right.$; Fig. $\left.4 B\right)$. Planned comparisons with paired-samples $t$ tests revealed that infusions of lidocaine resulted in a significantly lower discrimination ratio compared with saline in the preexposure condition $\left(t_{(11)}=3.739, p=0.003\right)$, but not the no preexposure condition $\left(t_{(11)}=0.886, p=0.405\right)$. Consistent with this, separate onesample $t$ tests revealed deficits in CMOR for animals in each condition (no preexposure: saline, $t_{(11)}=0.661, p=0.522$; lidocaine, $t_{(11)}=-0.347, p=0.735$; preexposure: lidocaine, $\left.t_{(11)}=-0.093, p=0.928\right)$, except when rats received saline after the multimodal preexposure session $\left(t_{(11)}=6.530, p<0.001\right)$.

\section{Experiment 2c: presample inactivation of PRh in PE/CMOR}

Temporary inactivation of PRh before the tactile sample phase of the PE/CMOR task abolished performance in preexposed rats. An analysis of the discrimination ratios with repeated-measures ANOVA revealed nonsignificant main effects of preexposure $\left(F_{(1,8)}=0.586, p=0.466\right)$ and drug $\left(F_{(1,8)}=1.204, p=0.304\right)$, but a significant preexposure $\times$ drug interaction term $\left(F_{(1,8)}=\right.$ 8.481, $p=0.020$; Fig. $4 C$ ). Post hoc analysis using paired-samples $t$ tests indicated that, compared with lidocaine, rats administered saline showed a significantly higher discrimination ratio in the preexposure condition $\left(t_{(8)}=3.083, p=0.015\right)$, but not in the no preexposure condition $\left(t_{(8)}=-1.113, p=0.298\right)$. Moreover, this pattern of effects was supported with separate one-sample $t$ tests demonstrating significant novel object preference in preexposed animals receiving saline $\left(t_{(8)}=3.405, p=0.009\right)$, but not in any other condition (no preexposure: saline, $t_{(8)}=-0.406$, $p=0.696$; lidocaine, $t_{(8)}=0.978, p=0.357$; preexposure: lidocaine, $\left.t_{(8)}=-0.142, p=0.891\right)$. 
Table 3. Control measures collected from the sample phase for each condition from Experiments 1-5

\begin{tabular}{|c|c|c|c|c|c|}
\hline \multirow[b]{2}{*}{ Experiment } & \multirow[b]{2}{*}{ Task/preexposure condition } & \multicolumn{2}{|l|}{ Saline } & \multicolumn{2}{|l|}{ Lidocaine } \\
\hline & & Total object exploration & Total phase duration & Total object exploration & Total phase duration \\
\hline \multirow[t]{3}{*}{$1 \mathrm{a}$} & CMOR & $20.88 \pm 0.99$ & $150.36 \pm 7.86$ & $19.49 \pm 1.16$ & $159.10 \pm 9.23$ \\
\hline & Tactile & $20.08 \pm 1.47$ & $145.99 \pm 10.77$ & $17.07 \pm 1.37$ & $160.27 \pm 7.47$ \\
\hline & Visual & $7.89 \pm 0.73$ & $180 \pm 0$ & $8.50 \pm 0.93$ & $180 \pm 0$ \\
\hline \multirow[t]{3}{*}{$1 \mathrm{~b}$} & CMOR & $8.89 \pm 1.05$ & $180 \pm 0$ & $7.54 \pm 0.82$ & $180 \pm 0$ \\
\hline & Tactile & $6.47 \pm 0.71$ & $180 \pm 0$ & $7.51 \pm 0.93$ & $180 \pm 0$ \\
\hline & Visual & $2.91 \pm 0.11$ & $180 \pm 0$ & $3.83 \pm 1.01$ & $180 \pm 0$ \\
\hline \multirow[t]{2}{*}{$2 a$} & No-PE & $19.86 \pm 1.41$ & $153.54 \pm 13.79$ & $16.48 \pm 1.53$ & $166.80 \pm 10.20$ \\
\hline & $\mathrm{PE}$ & $16.36 \pm 1.68$ & $171.93 \pm 8.11$ & $21.34 \pm 1.50$ & $143.86 \pm 11.21$ \\
\hline \multirow[t]{2}{*}{$2 b$} & No-PE & $19.19 \pm 1.78$ & $152.38 \pm 12.46$ & $19.26 \pm 1.38$ & $158.13 \pm 11.69$ \\
\hline & $\mathrm{PE}$ & $19.47 \pm 1.78$ & $142.80 \pm 12.62$ & $18.00 \pm 2.04$ & $143.51 \pm 54.62$ \\
\hline \multirow[t]{2}{*}{$2 c$} & No-PE & $19.13 \pm 1.88$ & $166.29 \pm 8.79$ & $18.17 \pm 1.46$ & $165.83 \pm 8.79$ \\
\hline & $\mathrm{PE}$ & $15.61 \pm 1.85$ & $174.06 \pm 4.19$ & $16.47 \pm 1.49$ & $160.39 \pm 9.74$ \\
\hline \multirow[t]{2}{*}{$2 d$} & No-PE & $9.30 \pm 0.90$ & $180 \pm 0$ & $10.09 \pm 1.56$ & $173.31 \pm 6.71$ \\
\hline & $\mathrm{PE}$ & $7.32 \pm 0.71$ & $180 \pm 0$ & $7.76 \pm 0.48$ & $180 \pm 0$ \\
\hline \multirow[t]{2}{*}{3} & No-PE & $21.63 \pm 1.17$ & $141.70 \pm 16.12$ & $19.71 \pm 1.43$ & $157.69 \pm 12.15$ \\
\hline & PE & $23.34 \pm 0.81$ & $147.78 \pm 14.17$ & $19.78 \pm 1.46$ & $172.13 \pm 3.84$ \\
\hline \multirow[t]{3}{*}{$4 a$} & CMOR & $9.31 \pm 0.59$ & $180 \pm 0$ & $8.14 \pm 0.83$ & $180 \pm 0$ \\
\hline & Tactile & $8.53 \pm 0.73$ & $180 \pm 0$ & $9.44 \pm 1.17$ & $180 \pm 0$ \\
\hline & Visual & $3.36 \pm 0.16$ & $180 \pm 0$ & $3.00 \pm 0.25$ & $180 \pm 0$ \\
\hline \multirow[t]{3}{*}{$4 b$} & CMOR & $7.80 \pm 0.63$ & $180 \pm 0$ & $8.16 \pm 0.99$ & $180 \pm 0$ \\
\hline & Tactile & $11.03 \pm 0.93$ & $180 \pm 0$ & $10.58 \pm 1.18$ & $180 \pm 0$ \\
\hline & Visual & $3.03 \pm 0.25$ & $180 \pm 0$ & $2.98 \pm 0.29$ & $180 \pm 0$ \\
\hline \multirow[t]{2}{*}{$5 a$} & No-PE & $16.72 \pm 1.87$ & $168.15 \pm 6.28$ & $16.29 \pm 1.21$ & $165.53 \pm 7.19$ \\
\hline & $\mathrm{PE}$ & $14.52 \pm 1.63$ & $176.41 \pm 3.20$ & $13.01 \pm 1.40$ & $173.24 \pm 4.50$ \\
\hline \multirow[t]{2}{*}{$5 b$} & No-PE & $10.58 \pm 0.71$ & $180 \pm 0$ & $9.71 \pm 0.59$ & $180 \pm 0$ \\
\hline & $\mathrm{PE}$ & $7.95 \pm 0.56$ & $180 \pm 0$ & $7.70 \pm 0.56$ & $180 \pm 0$ \\
\hline \multirow[t]{2}{*}{$5 c$} & No-PE & $13.70 \pm 1.97$ & $170.39 \pm 9.64$ & $9.70 \pm 0.99$ & $180 \pm 0$ \\
\hline & $\mathrm{PE}$ & $10.10 \pm 1.29$ & $180 \pm 0$ & $9.37 \pm 1.66$ & $180 \pm 0$ \\
\hline \multirow[t]{2}{*}{$5 d$} & No-PE & $14.17 \pm 2.59$ & $169.31 \pm 10.72$ & $10.90 \pm 2.28$ & $180 \pm 0$ \\
\hline & $\mathrm{PE}$ & $9.51 \pm 1.31$ & $180 \pm 0$ & $8.78 \pm 0.88$ & $180 \pm 0$ \\
\hline
\end{tabular}

Data are expressed as the mean \pm SEM of the total time in seconds spent exploring the objects and the total duration of the sample phase in seconds.

Experiment 2d: prechoice inactivation of PRh in PE/CMOR Rats performing CMOR after a multimodal preexposure session displayed significant deficits after local administration of lidocaine into PRh immediately before the visual choice phase. Analysis of the repeated-measures ANOVA indicated nonsignificant main effects of preexposure $\left(F_{(1,11)}=2.230, p=\right.$ $0.163)$ and drug $\left(F_{(1,11)}=4.206, p=0.065\right)$, but a significant drug $\times$ preexposure interaction $\left(F_{(1,11)}=10.433, p=0.008\right)$. Post hoc analysis with paired-samples $t$ tests indicated a significantly higher discrimination ratio for saline-treated compared with lidocaine-treated rats in the preexposure condition $\left(t_{(11)}=4.643, p=0.001\right)$, but not in the no preexposure condition $\left(t_{(11)}=-0.465, p=0.651\right.$; Fig. $\left.4 D\right)$. Consistent with these findings, the analysis of separate one-sample $t$ tests indicated impaired CMOR in all conditions (no preexposure: saline, $t_{(11)}=-0.572, p=0.579$; lidocaine, $t_{(11)}=-0.046$, $p=0.964$; preexposure: lidocaine, $\left.t_{(11)}=-2.150, p=0.055\right)$, except preexposed animals receiving infusions of saline $\left(t_{(11)}=3.259, p=0.008\right)$. Examination of the object exploration control measure during the sample phase revealed a significant main effect of preexposure $\left(F_{(1,11)}=5.965, p=\right.$ 0.033 ), with rats in the preexposure condition spending, on average, less time exploring the objects during the sample phase. Importantly, the drug $\times$ preexposure interaction term was not significant $\left(F_{(1,11)}=0.027, p=0.873\right)$ and pairedsamples $t$ tests indicated no difference in object exploration between saline-treated and lidocaine-treated animals in the preexposure $\left(t_{(11)}=-0.658, p=0.524\right)$ and no preexposure conditions $\left(t_{(11)}=-0.421, p=0.682\right)$.
Experiment 3: bilateral inactivation of PRh on PE/CMOR task with $1 \mathrm{~h}$ retention delay

The differential involvement during the sample phase of $\mathrm{PRh}$ in Experiments 1 and 2 suggests that allowing rats to experience the tactile and visual features of an object simultaneously fundamentally changes the way the object is processed and represented in the brain. We hypothesize that multimodal preexposure gives rise to the formation of a crossmodal association and subsequent storage of a multisensory object representation in PRh for future use. However, given the important role that PRh plays in mnemonic processes (Buckley and Gaffan, 2006; Murray et al., 2007; Winters et al., 2008), it could be argued that PRh is necessary during the sample phase of the PE/CMOR task to facilitate performance across the extended retention delay ( $3 \mathrm{~h}$ in Experiment 2 vs $1 \mathrm{~h}$ in Experiment 1). To test this, for Experiment 3, we reduced the retention delay of the PE/CMOR task to $1 \mathrm{~h}$ and gave intra-PRh infusions of lidocaine before the tactile sample phase. Analysis of the discrimination ratios using a repeated-measures ANOVA revealed a nonsignificant main effect of preexposure $\left(F_{(1,9)}=4.331, p=0.067\right)$, a significant main effect of drug $\left(F_{(1,9)}=15.559, p=0.006\right)$, and a nonsignificant preexposure $X$ drug interaction $\left(F_{(1,9)}=1.707, p=0.224\right)$. Planned comparisons with paired-samples $t$ tests indicated that rats receiving intra-PRh infusions of lidocaine performed significantly worse than when they received saline in the preexposure condition $\left(t_{(9)}=3.549, p=0.006\right)$, but not in the no preexposure condition $\left(t_{(9)}=0.495, p=0.632\right.$; Fig. 5). This pattern of effects is congruous with results from separate one-sample $t$ tests demonstrating intact recognition in all conditions (no preexposure: saline, $t_{(9)}$ 
Table 4. Control measures collected from the choice phase for each condition from Experiments 1-5

\begin{tabular}{|c|c|c|c|}
\hline \multirow[b]{2}{*}{ Experiment } & \multirow{2}{*}{$\begin{array}{l}\text { Task/preexposure } \\
\text { condition }\end{array}$} & \multicolumn{2}{|c|}{ Total object exploration } \\
\hline & & Saline & Lidocaine \\
\hline \multirow[t]{3}{*}{$1 \mathrm{a}$} & CMOR & $3.24 \pm 0.30$ & $3.14 \pm 0.27$ \\
\hline & Tactile & $12.22 \pm 1.42$ & $13.11 \pm 2.02$ \\
\hline & Visual & $2.35 \pm 0.26$ & $2.74 \pm 0.32$ \\
\hline \multirow[t]{3}{*}{$1 \mathrm{~b}$} & CMOR & $1.37 \pm 0.14$ & $1.30 \pm 0.13$ \\
\hline & Tactile & $3.94 \pm 0.67$ & $4.89 \pm 0.89$ \\
\hline & Visual & $1.18 \pm 0.24$ & $1.03 \pm 0.14$ \\
\hline \multirow[t]{2}{*}{$2 a$} & No-PE & $3.55 \pm 0.75$ & $3.50 \pm 0.55$ \\
\hline & PE & $5.77 \pm 0.96$ & $3.38 \pm 0.53$ \\
\hline \multirow[t]{2}{*}{$2 b$} & No-PE & $3.79 \pm 0.47$ & $3.46 \pm 0.46$ \\
\hline & PE & $3.68 \pm 0.53$ & $4.11 \pm 0.58$ \\
\hline \multirow[t]{2}{*}{$2 c$} & No-PE & $3.22 \pm 0.65$ & $3.57 \pm 0.71$ \\
\hline & PE & $4.69 \pm 0.82$ & $3.79 \pm 0.52$ \\
\hline \multirow[t]{2}{*}{$2 d$} & No-PE & $1.32 \pm 0.15$ & $1.40 \pm 0.13$ \\
\hline & PE & $1.63 \pm 0.11$ & $1.51 \pm 0.15$ \\
\hline \multirow[t]{2}{*}{3} & No-PE & $3.33 \pm 0.50$ & $4.09 \pm 0.43$ \\
\hline & PE & $4.48 \pm 0.98$ & $4.85 \pm 0.72$ \\
\hline \multirow[t]{3}{*}{$4 a$} & CMOR & $1.89 \pm 0.18$ & $1.32 \pm 0.08$ \\
\hline & Tactile & $4.41 \pm 0.83$ & $3.35 \pm 0.70$ \\
\hline & Visual & $1.12 \pm 0.08$ & $1.25 \pm 0.10$ \\
\hline \multirow[t]{3}{*}{$4 b$} & CMOR & $1.79 \pm 0.18$ & $1.57 \pm 0.13$ \\
\hline & Tactile & $6.26 \pm 0.88$ & $4.79 \pm 1.06$ \\
\hline & Visual & $1.37 \pm 0.13$ & $1.53 \pm 0.16$ \\
\hline \multirow[t]{2}{*}{$5 a$} & No-PE & $2.89 \pm 0.35$ & $2.75 \pm 0.25$ \\
\hline & PE & $2.92 \pm 0.33$ & $3.02 \pm 0.27$ \\
\hline \multirow[t]{2}{*}{$5 b$} & No-PE & $1.21 \pm 0.14$ & $1.41 \pm 0.10$ \\
\hline & PE & $1.43 \pm 0.14$ & $1.43 \pm 0.19$ \\
\hline \multirow[t]{2}{*}{$5 c$} & No-PE & $1.43 \pm 0.14$ & $1.46 \pm 0.26$ \\
\hline & PE & $1.82 \pm 0.35$ & $1.55 \pm 0.19$ \\
\hline \multirow[t]{2}{*}{$5 d$} & No-PE & $1.99 \pm 0.29$ & $1.50 \pm 0.15$ \\
\hline & PE & $1.63 \pm 0.25$ & $1.53 \pm 0.27$ \\
\hline
\end{tabular}

Data are expressed as the mean \pm SEM of the total time in seconds spent exploring the objects.

$=5.022, p=0.001$; lidocaine, $t_{(9)}=4.775, p=0.001$; preexposure: saline, $\left.t_{(9)}=3.935, p=0.003\right)$, except when preexposed rats received infusions of lidocaine $\left(t_{(9)}=-0.029, p=\right.$ 0.987). Therefore, the effects in Experiment 2 do not appear to be the result of the difference in retention delay length between CMOR and PE/CMOR tasks.

\section{Experiment 4: bilateral inactivation of PPC in CMOR and unimodal SOR tasks}

For an investigation of the temporal contribution of PPC to CMOR, rats with bilateral cannulas targeted toward PPC were administered infusions of saline or lidocaine immediately before the sample or choice phases of the CMOR task. The retention delay was $1 \mathrm{~h}$ for these experiments.

\section{Experiment 4a: presample inactivation of PPC in CMOR}

Rats receiving infusions of lidocaine into PPC before the sample phase displayed impairments in tactile SOR and CMOR tasks. Repeated-measures ANOVA revealed a nonsignificant main effect of task $\left(F_{(2,22)}=3.452, p=0.050\right)$, but significant main effects of drug $\left(F_{(1,11)}=15.280, p=0.002\right)$ and task $\times$ drug interaction $\left(F_{(2,22)}=8.465, p=0.002\right)$. Post hoc analysis with paired-samples $t$ tests indicated that lidocaine administered into PPC produced significantly lower discrimination ratios compared with saline when rats were tested in the tactile SOR $\left(t_{(11)}=\right.$ $3.269, p=0.007)$ and $\operatorname{CMOR}\left(t_{(11)}=6.113, p<0.001\right)$ tasks (Fig. $6 A)$. These results were further supported by separate one-sample $t$ tests, which showed intact object recognition in all conditions (visual: saline, $t_{(11)}=5.888, p<0.001$; lidocaine, $t_{(11)}=7.894$, $p<0.001$; tactile: saline, $t_{(11)}=5.412, p<0.001$; crossmodal: saline, $\left.t_{(11)}=5.314, p<0.001\right)$, except when rats received infusions of lidocaine before the tactile $\operatorname{SOR}\left(t_{(11)}=1.052, p=0.316\right)$ and $\operatorname{CMOR}\left(t_{(11)}=0.313, p=0.760\right)$ tasks.

\section{Experiment 4b: prechoice inactivation of PPC in CMOR}

Transient inactivation of PPC immediately preceding the choice phase produced deficits in tactile SOR and CMOR. Repeatedmeasures ANOVA indicated significant main effects of task $\left(F_{(2,18)}=7.103, p=0.005\right)$ and $\operatorname{drug}\left(F_{(1,9)}=16.383, p=0.003\right)$, but a nonsignificant task $\times$ drug interaction $\left(F_{(2,18)}=2.039, p=\right.$ $0.159)$. Planned comparisons with paired-samples $t$ tests revealed significantly lower discrimination ratios on lidocaine compared with saline trials when animals were tested on the tactile SOR $\left(t_{(9)}=4.435, p=0.002\right)$ and $\operatorname{CMOR}\left(t_{(9)}=2.731, p=0.023\right)$ tasks (Fig. 6B). Accordingly, separate one-sample $t$ tests showed intact object recognition in all conditions (visual: saline, $t_{(9)}=3.936, p=0.003$; lidocaine, $t_{(9)}=2.394, p=0.040$; tactile: saline, $t_{(9)}=10.955, p<0.001$; lidocaine, $t_{(9)}=2.695, p=0.025$; crossmodal: saline, $\left.t_{(9)}=3.073, p=0.013\right)$, except when rats received infusions of lidocaine before the CMOR task $\left(t_{(9)}=-1.098, p=0.301\right)$.

Experiment 5: bilateral inactivation of PPC in PE/CMOR task The pattern of results from Experiment 4 are consistent with findings from Winters and Reid (2010) demonstrating a pivotal role for PPC in processing the tactile aspect of CMOR. Interestingly, the necessity of PPC during the visual choice phase of the CMOR task suggests that the previously stored tactile representation is either housed in or accessed via PPC. To evaluate the role of PPC in CMOR after multimodal preexposure to the to-beremembered objects, rats were implanted with bilateral cannulas directed toward PPC and given infusions of saline or lidocaine immediately before or after the preexposure phase or before the sample or choice phases of the PE/CMOR task. The retention delay was $3 \mathrm{~h}$.

\section{Experiment 5a: inactivation of PPC before the preexposure phase of PE/CMOR}

Reversible lesions of PPC before multimodal preexposure had no effect on CMOR. Repeated-measures ANOVA revealed a significant main effect of preexposure $\left(F_{(1,10)}=16.558, p=0.002\right)$, but a nonsignificant main effect of drug $\left(F_{(1,10)}=1.088, p=0.322\right)$ and a nonsignificant preexposure $\times$ drug interaction $\left(F_{(1,10)}=\right.$ $0.037, p=0.855$; Fig. $7 A$ ). Planned comparisons with pairedsamples $t$ tests revealed that infusions of lidocaine had no impact on the discrimination ratio of animals in the no preexposure $\left(t_{(10)}=0.452, p=0.661\right)$ or preexposure conditions $\left(t_{(10)}=\right.$ $0.764, p=0.462)$. This interpretation was further corroborated using separate one-sample $t$ tests because rats in the preexposure condition displayed intact CMOR regardless of drug treatment (saline, $t_{(10)}=5.424, p<0.001$; lidocaine, $t_{(10)}=5.935, p<$ 0.001 ), whereas omitting preexposure impaired performance outright (saline, $t_{(10)}=1.344, p=0.209$; lidocaine, $t_{(10)}=0.320$, $p=0.755)$.

\section{Experiment 5b: inactivation of PPC after the preexposure phase of PE/CMOR}

Lidocaine infused into the PPC immediately after the multimodal preexposure phase had no effect on CMOR. Repeated-measures ANOVA revealed a significant main effect of preexposure $\left(F_{(1,8)}=15.479, p=0.004\right)$, but a nonsignificant main effect of drug $\left(F_{(1,8)}=1.661, p=0.233\right)$ and nonsignificant preexposure $\times$ drug interaction $\left(F_{(1,8)}=0.396, p=0.547\right.$; Fig. 

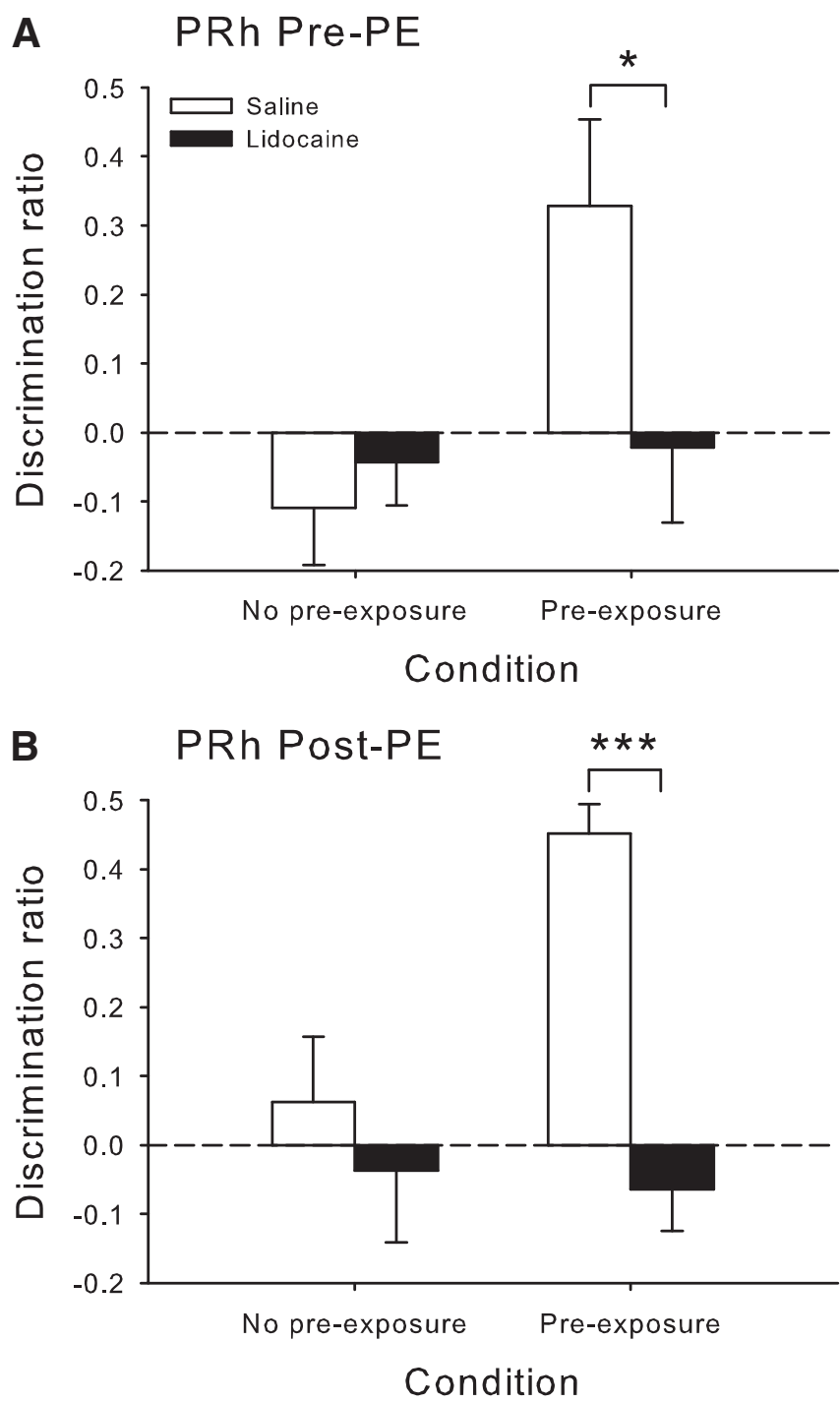

C PRh Pre-Sample

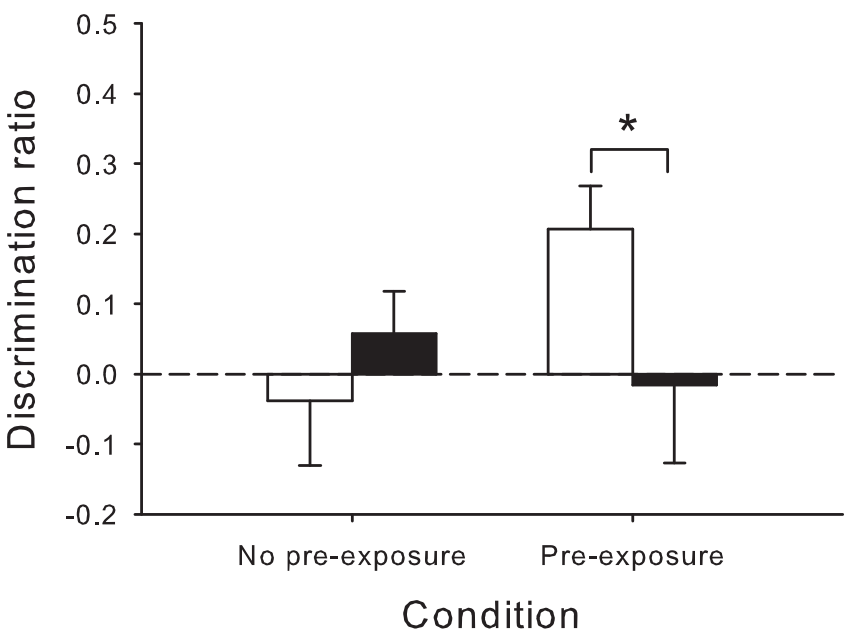

D PRh Pre-Choice

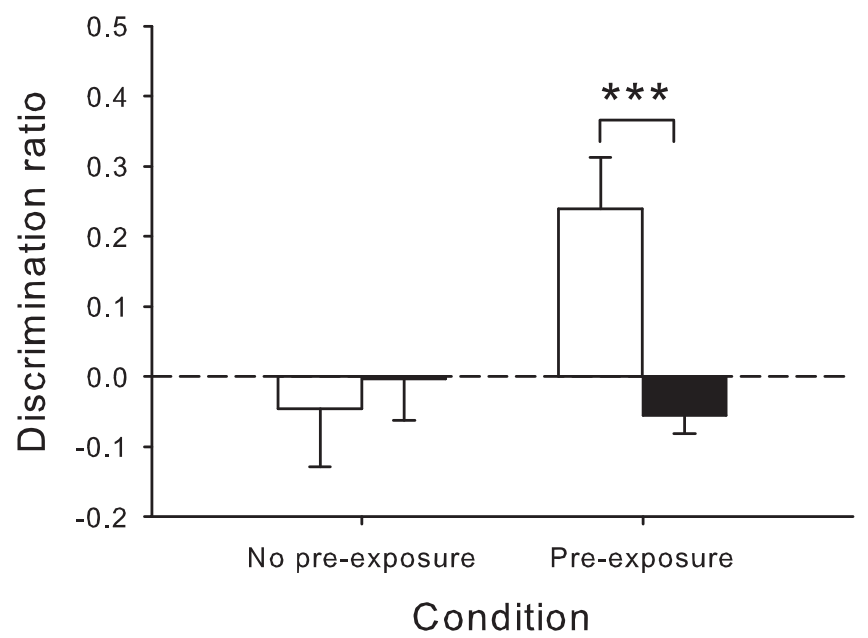

Figure 4. Object recognition performance in the PE/CMOR task by rats receiving infusions of saline or lidocaine into PRh immediately before the preexposure phase $(n=13 ; A)$, immediately after the preexposure phase $(n=12 ; \boldsymbol{B})$; immediately before the sample phase $(n=9 ; \boldsymbol{C})$, or immediately before the choice phase $(n=12 ; \boldsymbol{D})$. For all experiments, there was a $3 \mathrm{~h}$ retention delay between the sample and choice phases; with this delay length, normal rats typically fail to show novelty preference in the CMOR task without multimodal preexposure. Data are presented as the average discrimination ratio ( \pm SEM). ${ }^{*} p<0.05 ;{ }^{* *} p<0.01$, saline versus lidocaine.

7B). Planned comparisons with paired-samples $t$ tests indicated that lidocaine treatment did not significantly alter performance in the preexposure $\left(t_{(8)}=-0.526, p=0.613\right)$ or no preexposure conditions $\left(t_{(8)}=-1.622, p=0.143\right)$. Additional separate one-sample $t$ tests supported this interpretation because animals in the preexposure condition successfully performed CMOR (saline, $t_{(8)}=2.742$, $p=0.025$; lidocaine, $t_{(8)}=6.229, p<0.001$ ), whereas omitting the preexposure phase produced a deficit in recognition regardless of drug administered (saline, $t_{(8)}=-1.200, p=0.265$; lidocaine, $\left.t_{(8)}=0.695, p=0.506\right)$. Although analysis of the repeated-measures ANOVA for object exploration during the sample phase indicated a significant main effect of preexposure $\left(F_{(1,8)}=24.055, p=0.001\right)$, this is unlikely to account for the lack of effect produced by lidocaine because there was a nonsignificant preexposure $\times$ drug interaction $\left(F_{(1,8)}=0.757, p=0.547\right)$ and no significant differences between saline- and lidocaine-treated animals in the preexposure $\left(t_{(8)}=\right.$ $0.570, p=0.584)$ and no preexposure conditions $\left(t_{(8)}=1.683\right.$, $p=0.131)$.
Experiment 5c: presample inactivation of PPC on PE/CMOR

Performance on the PE/CMOR task was unaffected by administration of lidocaine into PPC immediately before the tactile sample phase. Repeated-measures ANOVA revealed a significant main effect of preexposure $\left(F_{(1,10)}=30.275, p<0.001\right)$, but a nonsignificant main effect of drug $\left(F_{(1,10)}=2.245, p=\right.$ $0.165)$ and a nonsignificant preexposure $\times$ drug interaction $\left(F_{(1,10)}=1.198, p=0.299\right.$; Fig. $\left.7 C\right)$. Planned comparisons with paired-samples $t$ tests demonstrated that lidocaine did not affect performance in the preexposure $\left(t_{(10)}=0.556, p=\right.$ $0.591)$ or no preexposure conditions $\left(t_{(10)}=1.524, p=0.158\right)$ relative to saline treatment. Moreover, separate one-sample $t$ tests indicated intact object recognition for animals in the preexposure condition (saline, $t_{(10)}=11.061, p<0.001$ lidocaine, $\left.t_{(10)}=4.869, p=0.001\right)$, whereas animals in the no preexposure condition were unable to recognize the sample object after the $3 \mathrm{~h}$ delay (saline, $t_{(10)}=1.226, p=0.248$ lidocaine, $\left.t_{(10)}=-1.150, p=0.277\right)$. 


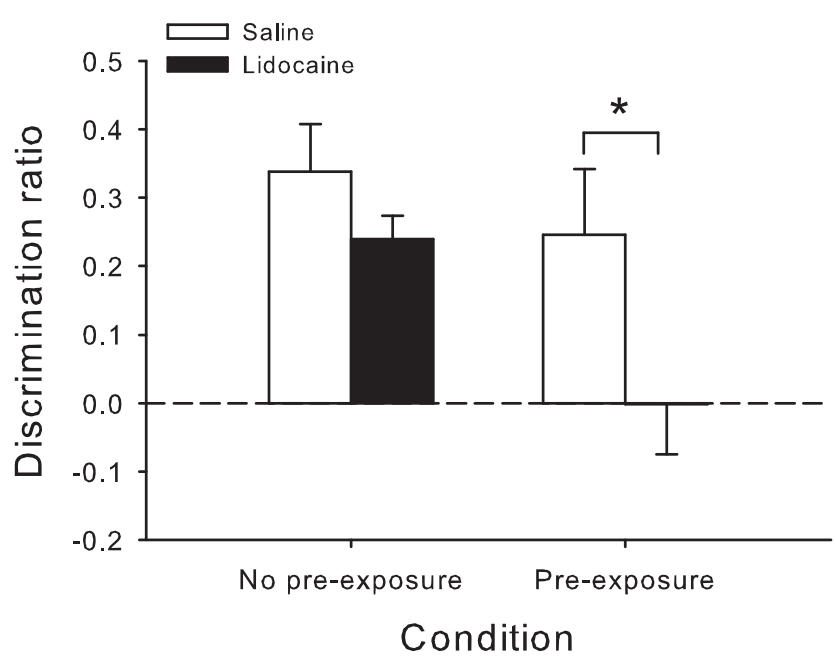

Figure 5. Object recognition performance of rats receiving infusions of saline or lidocaine into PRh immediately before the sample phase of the PE/CMOR task with a $1 \mathrm{~h}$ retention delay between the sample and choice phases $(n=10)$. This experiment controls for the difference in retention delays between $C M O R$ (Experiment 1 ) and PE/CMOR (Experiment 2) tasks. Data are presented as the average discrimination ratio ( \pm SEM). ${ }^{* *} p<0.01$, saline versus lidocaine.

Experiment 5d: prechoice inactivation of PPC on PE/CMOR Rats receiving multimodal preexposure performed equally well on CMOR after receiving intra-PPC infusions of saline or lidocaine before the visual choice phase. Analysis of the discrimination ratios using a repeated-measures ANOVA revealed a significant main effect of preexposure $\left(F_{(1,6)}=25.688, p=\right.$ $0.002)$, but a nonsignificant main effect of drug $\left(F_{(1,6)}=0.236\right.$, $p=0.644)$ and preexposure $\times$ drug interaction $\left(F_{(1,6)}=0.058\right.$, $p=0.817$; Fig. $7 D)$. Planned comparisons with paired-samples $t$ tests indicated that lidocaine administration had no impact on the CMOR of animals in the no preexposure $\left(t_{(6)}=0.618, p=\right.$ $0.560)$ or preexposure conditions $\left(t_{(6)}=0.221, p=0.832\right)$. Furthermore, separate one-sample $t$ tests were consistent with these results because rats in the preexposure condition displayed a preference for the novel object (saline, $t_{(6)}=4.236, p=0.005$ lidocaine, $t_{(6)}=5.728, p=0.001$ ), whereas rats in the no preexposure condition did not (saline, $t_{(6)}=0.097, p=0.926$ lidocaine, $\left.t_{(6)}=0.897, p=0.404\right)$. A significant main effect of preexposure was seen upon analysis of the object exploration control measures for the sample phase $\left(F_{(1,6)}=19.434, p=\right.$ 0.005). Although rats in the preexposure condition typically spent less time exploring the objects during the sample phase, paired-samples $t$ tests indicated no difference in object exploration between saline- and lidocaine-treated animals in the preexposure $\left(t_{(6)}=0.516, p=0.624\right)$ and no preexposure conditions $\left(t_{(6)}=0.883, p=0.441\right)$.

\section{Experiment 6: analysis of Fos-positive cells after multimodal object preexposure}

Fos-positive cells were counted in PRh (areas 35 and 36) and PPC, as well as two additional control areas (Aud and M1/M2), after multimodal preexposure to 30 objects. Repeated-measures ANOVA indicated nonsignificant main effects of brain region $(F<1)$ and condition $(F<1)$, but a significant region $\times$ condition interaction $\left(F_{(3,42)}=3.4, p=0.026\right)$. Independent-samples $t$ tests comparing Fos-positive counts between control and objectexposed rats for each brain region revealed a significant difference for only PRh $\left(t_{(14)}=3.33, p=0.005\right)$; object exposure in the $\mathrm{Y}$-apparatus induced a significant upregulation of Fos compared

\section{A PPC Pre-Sample}

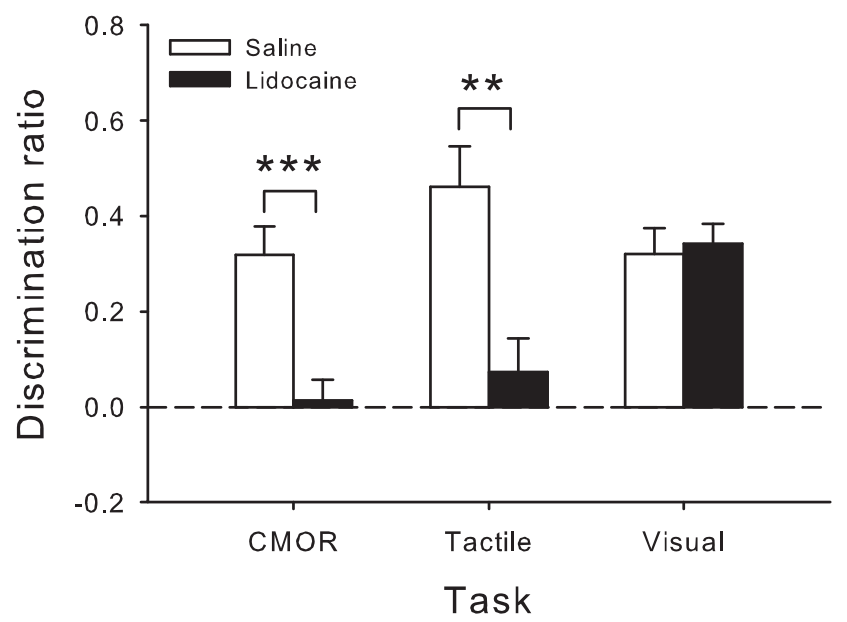

B PPC Pre-Choice

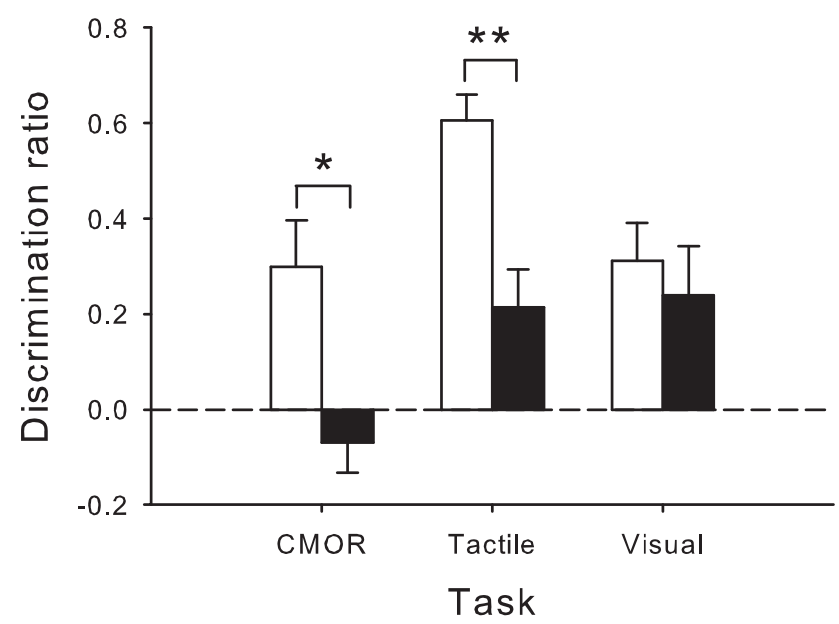

Figure 6. Object recognition performance of rats administered saline or lidocaine into PPC immediately before the sample phase of the CMOR, tactile, and visual SOR tasks $(n=12 ; A)$ or immediately before the choice phase of the CMOR, tactile, and visual SOR tasks $(n=10 ; \boldsymbol{B})$. Retention delay in all conditions was $1 \mathrm{~h}$. Data are presented as the average discrimination ratio ( \pm SEM). ${ }^{*} p<0.05 ;{ }^{* *} p<0.01 ;{ }^{* * *} p<0.001$, saline versus lidocaine.

with empty apparatus exploration (Fig. 8). To further assess Fos expression levels within $\mathrm{PRh}$, a topographic analysis was performed, revealing a significant condition $\times$ area $\times$ level interaction $\left(F_{(3,42)}=7.57, p<0.001\right.$; Fig. 9). Within PRh area 35 (Fig. $9 A)$, object exposure significantly increased Fos expression at the midrostral $\left(t_{(14)}=3.01, p=0.009\right)$ and midcaudal levels $\left(t_{(14)}=\right.$ $3.09, p=0.008)$, whereas significant increases were seen in area 36 (Fig. $9 B$ ) at both the most anterior $\left(t_{(14)}=3.04, p=0.009\right)$ and posterior $\left(t_{(14)}=3.95, p=0.001\right)$ levels analyzed. The object exploration means for the exposed group are presented in Table 5; a one-way ANOVA indicated a significant main effect of object, with rats exploring less as object exposure trials increased $\left(F_{(29,203)}=2.35, p<0.001\right)$.

\section{Experiment 7: analysis of Fos-positive cells after tactile sample phase}

Given our findings from the lidocaine experiments and from Experiment 6, we also assessed Fos expression in PRh after tactile exposure to 30 objects (analogous to the tactile sample phase in CMOR) when rats had been exposed to the multisensory features 


\section{A PPC Pre-PE}

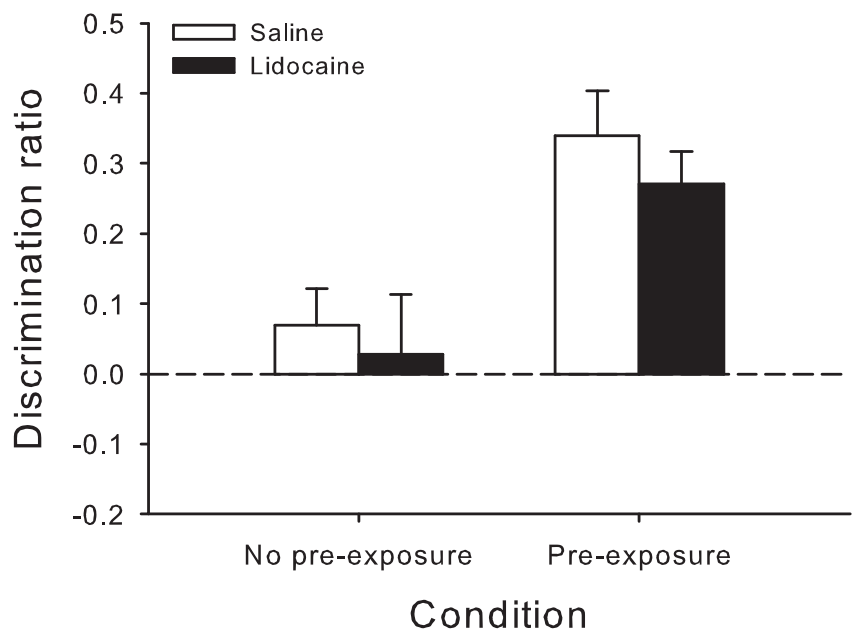

B PPC Post-PE

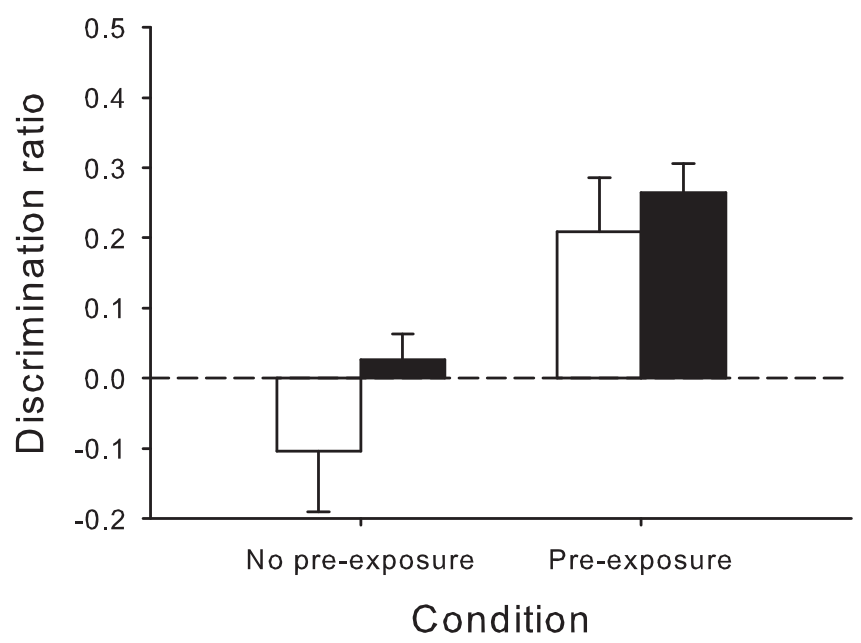

C

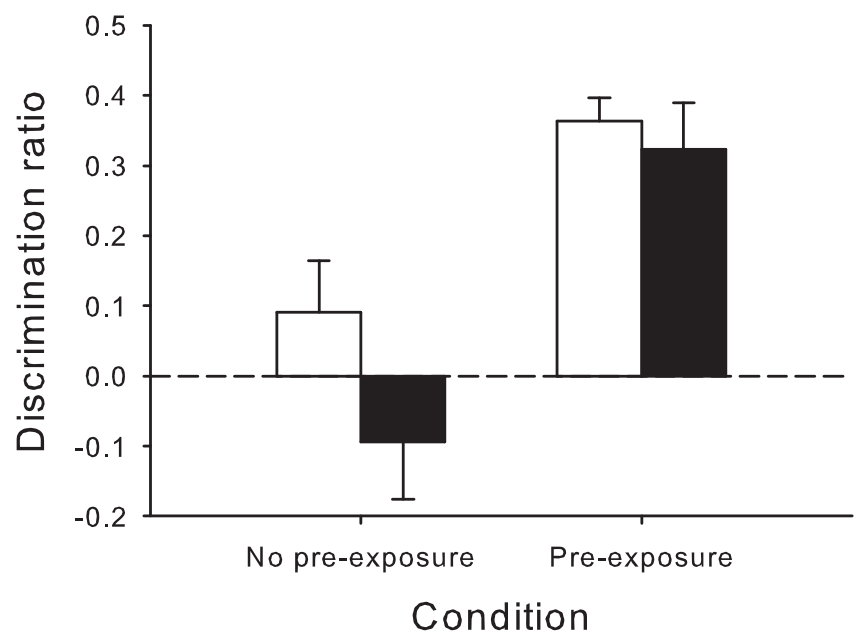

D

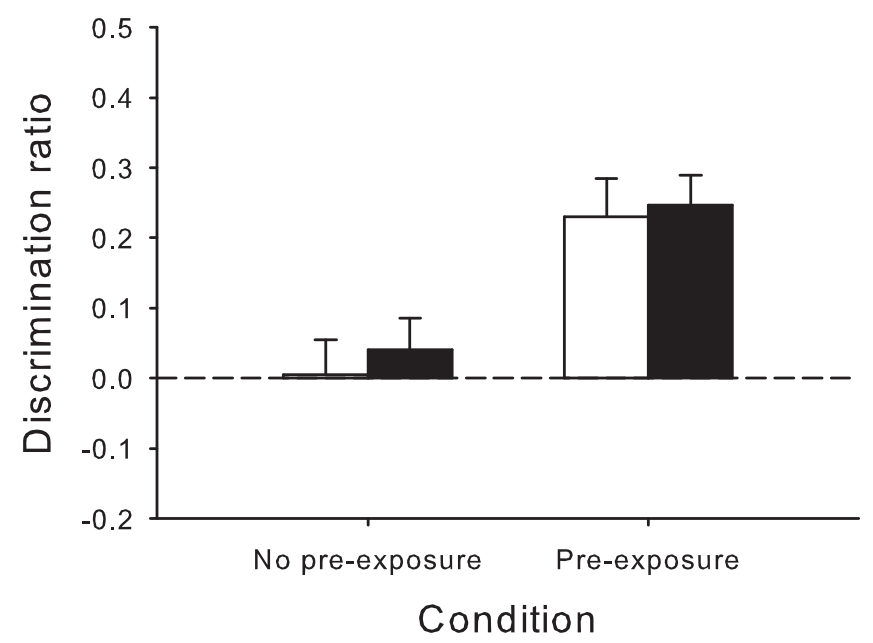

Figure 7. Object recognition performance in the PE/CMOR task by rats receiving infusions of saline or lidocaine into PPC immediately before the preexposure phase $(n=11 ; A)$, immediately after the preexposure phase $(n=9 ; \boldsymbol{B})$, immediately before the sample phase $(n=11 ; \boldsymbol{C})$, or immediately before the choice phase $(n=7 ; \boldsymbol{D})$. For all experiments, there was a $3 \mathrm{~h}$ retention delay between the sample and choice phases with this delay length. Normal rats typically fail to show novelty preference in the CMOR task without multimodal preexposure. Data are presented as the average discrimination ratio ( \pm SEM).

of the same objects $24 \mathrm{~h}$ prior (analogous to the PE/CMOR task) or when they had not received such preexposure. We predicted that there would be significantly higher Fos expression in PRh when rats had been preexposed and then subjected to tactile exploration of the same objects, consistent with our findings with lidocaine that PRh appears to become more essentially involved in the performance of the CMOR task when rats have had multimodal preexposure to the to-be-remembered object. The data were consistent with this prediction (Fig. 10). The three-way topographic analysis revealed a significant main effect of exposure condition $\left(F_{(3,12)}=24.53, p<0.001\right)$, but the interactions were not statistically significant. When collapsed across all rostralcaudal levels and areas 35 and 36, PRh Fos expression was significantly higher in the preexposure/sample condition compared with all other conditions (no preexposure/sample: $\left(t_{(6)}=6.59\right.$, $p<0.001)$; no preexposure/no sample: $\left(t_{(6)}=6.66, p<0.001\right)$; preexposure/no sample: $\left(t_{(6)}=9.09, p<0.001\right)$. Expression in preexposure/no sample was also significantly higher than in no preexposure/no sample $\left(t_{(6)}=4.29, p=0.005\right)$. All other comparisons were nonsignificant. The object exploration means for the various exposure groups are presented in Table 5; separate two-way (object $\times$ group) ANOVAs run on the data from the preexposure and sample phases indicated significant main effects of object, with rats exploring less as object exposure trials increased (preexposure: $F_{(29,174)}=2.81, p<0.001$; sample: $\left.F_{(29,174)}=2.65, p<0.001\right)$, but the main effect of group and the interaction were both nonsignificant.

\section{Discussion}

The results of the current study present an intriguing pattern of involvement for two cortical areas previously implicated in rat CMOR. Whereas PPC activity in both the sample and choice phases appears to be essential for CMOR and tactile SOR task performance, it does not appear to be necessary for visual SOR or for CMOR when rats have received multimodal preexposure to the to-be-remembered objects. In contrast, PRh involvement appears to be even more restricted for CMOR and visual SOR task performance, being required only during the choice phase of the former, but this cortical region assumes a ubiquitous role when rats are preexposed to the multisensory features of the to-be- 


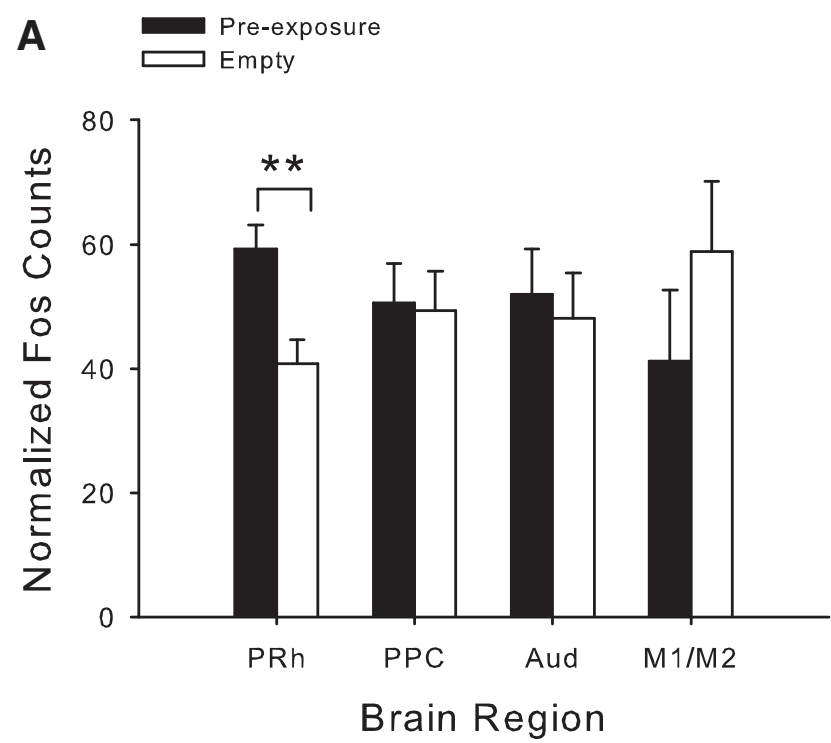

\section{B PRh - Empty}

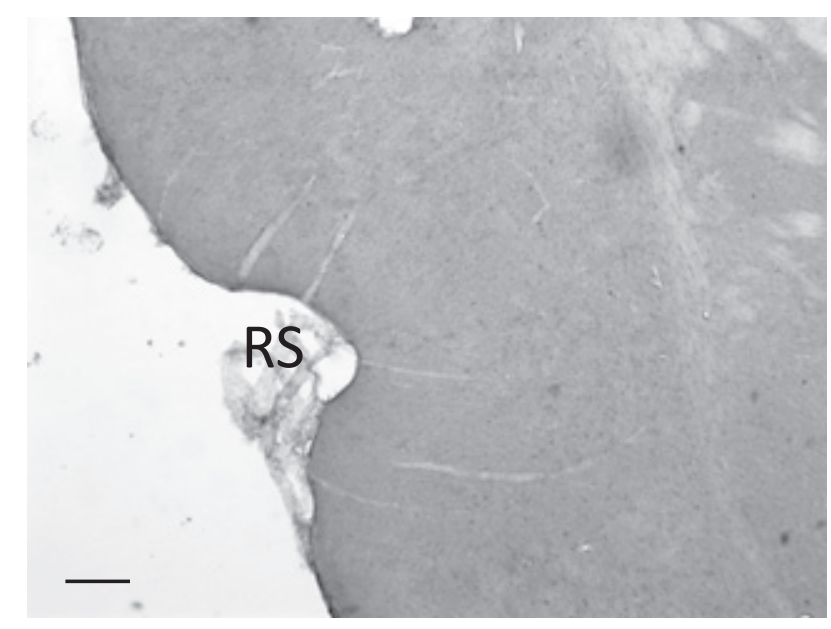

\section{c PRh - Pre-exposure}

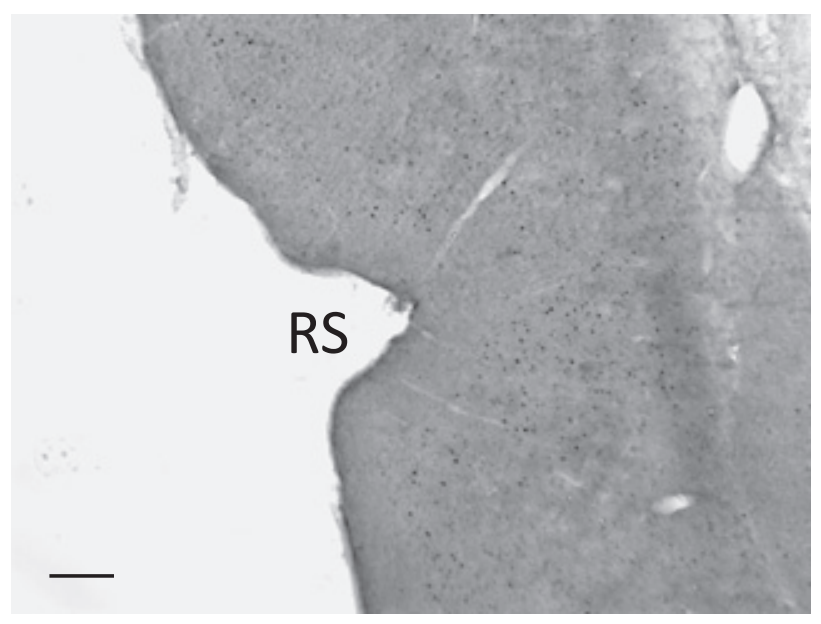

Figure 8. $\quad \boldsymbol{A}$, Fos expression levels in PRh, PPC, primary auditory (Aud), and motor (M1 and M2) cortex from rats exposed to 30 novel objects (visual and tactile exploration allowed; preexposure, black bars; $n=8$ ) compared with rats exposed to the empty apparatus for the same

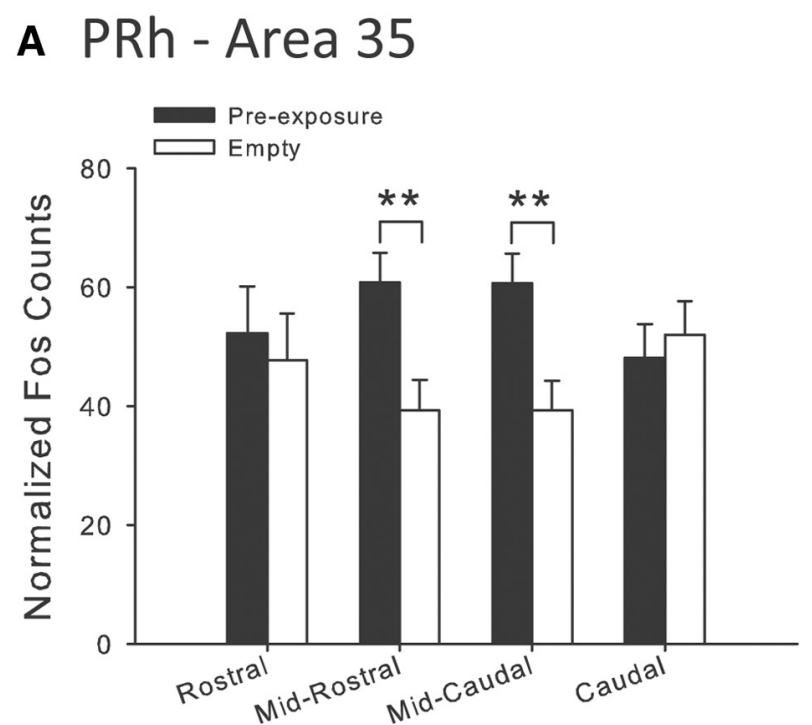

PRh Region (Area 35)
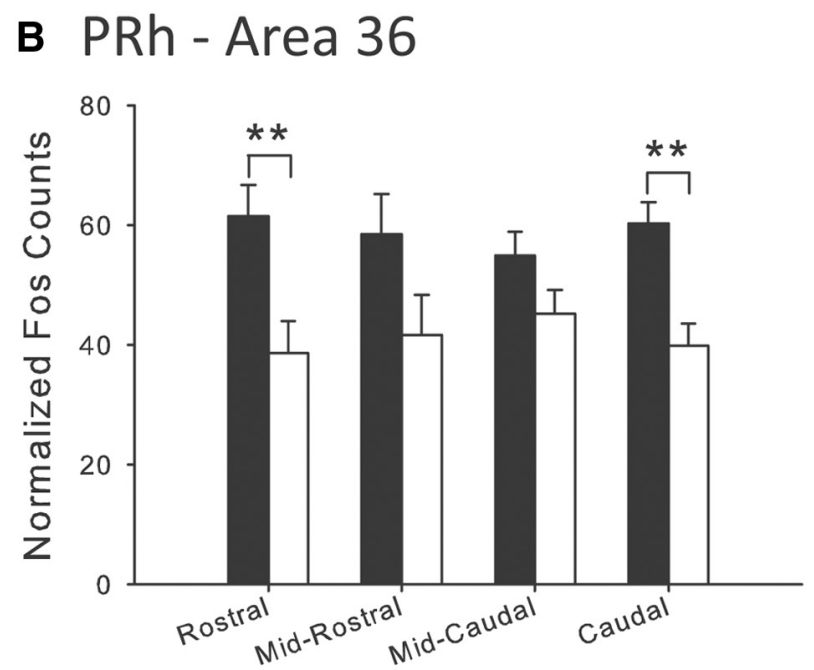

PRh Region (Area 36)

Figure 9. Topographic Fos expression levels in PRh areas $35(\boldsymbol{A})$ and $36(\boldsymbol{B})$ from rats exposed to 30 novel objects (visual and tactile exploration allowed; preexposure, black bars; $n=8$ ) compared with rats exposed to the empty apparatus for the same amount of time ("Empty," white bars; $n=8) 1 \mathrm{~h}$ before being killed. Significant upregulation was observed in the middle portions of PRh area 35 , whereas area 36 displayed the greatest increases in the rostral and caudal regions. Normalized counts of Fos-positive cells are presented as mean \pm SEM. ${ }^{* *} p<0.01$.

remembered objects. This pattern of behavioral results is supported by immediate early gene imaging data showing elevated Fos expression in PRh after multisensory object exploration. These findings complement a previous study indicating a functional interaction between PPC and PRh in the CMOR task

amount of time ("Empty," white bars; $n=8$ ) $1 \mathrm{~h}$ before being killed. Significant upregulation was observed only in PRh. Normalized counts of Fos-positive cells are presented as mean \pm SEM. B, C, Microphotographs ( $5 \times$ magnification) of representative slices illustrating Fosimmunoreactivity in PRh $(\sim 5.2 \mathrm{~mm}$ posterior to bregma) from a rat in the empty $(\boldsymbol{B})$ and preexposure $(\boldsymbol{C})$ conditions; note the substantially greater number of darkly stained cells in $\boldsymbol{C}$. ${ }^{* *} p<0.01$. RS, Rhinal sulcus. Scale bar, $200 \mu \mathrm{m}$. 
Table 5. Total object exploration collected for each of 30 trials from each condition for Experiments 6 and 7

\begin{tabular}{|c|c|c|c|c|c|}
\hline \multirow[b]{2}{*}{ Object } & \multicolumn{3}{|c|}{ Preexposure object exploration } & \multicolumn{2}{|c|}{ Sample object exploration } \\
\hline & $\begin{array}{l}\text { PE group } \\
\text { (Experiment 6) }\end{array}$ & $\begin{array}{l}\text { PE/no sample group } \\
\text { (Experiment } 7 \text { ) }\end{array}$ & $\begin{array}{l}\text { PE/sample group } \\
\text { (Experiment } 7 \text { ) }\end{array}$ & $\begin{array}{l}\text { No PE/sample group } \\
\text { (Experiment 7) }\end{array}$ & $\begin{array}{l}\text { PE/sample group } \\
\text { (Experiment } 7 \text { ) }\end{array}$ \\
\hline 1 & 10 & 10 & 10 & $22.92 \pm 1.31$ & $16.49 \pm 2.48$ \\
\hline 2 & 10 & 10 & $9.42 \pm 0.67$ & $17.72 \pm 1.80$ & $17.32 \pm 2.71$ \\
\hline 3 & 10 & $9.76 \pm 0.30$ & $9.54 \pm 0.30$ & $20.57 \pm 1.67$ & $18.74 \pm 2.25$ \\
\hline 4 & $9.64 \pm 0.27$ & 10 & $8.94 \pm 1.10$ & $18.94 \pm 1.80$ & $13.57 \pm 3.34$ \\
\hline 5 & $8.23 \pm 0.94$ & $8.18 \pm 1.46$ & $8.07 \pm 1.99$ & $13.81 \pm 1.12$ & $15.50 \pm 3.61$ \\
\hline 6 & $6.83 \pm 1.04$ & $7.19 \pm 1.90$ & $9.39 \pm 0.68$ & $16.81 \pm 0.80$ & $14.63 \pm 4.44$ \\
\hline 7 & $9.72 \pm 0.35$ & $7.96 \pm 2.08$ & 10 & $15.98 \pm 3.83$ & $18.39 \pm 4.35$ \\
\hline 8 & $8.51 \pm 0.89$ & $7.17 \pm 2.12$ & $7.29 \pm 1.06$ & $14.14 \pm 2.94$ & $16.85 \pm 3.01$ \\
\hline 9 & $8.37 \pm 0.88$ & $7.20 \pm 2.21$ & $7.31 \pm 2.32$ & $11.54 \pm 2.95$ & $16.94 \pm 4.15$ \\
\hline 10 & 10 & $9.00 \pm 1.07$ & $8.63 \pm 1.44$ & $10.59 \pm 3.48$ & $9.59 \pm 2.74$ \\
\hline 11 & $9.70 \pm 0.36$ & $3.47 \pm 1.47$ & $6.37 \pm 1.71$ & $12.16 \pm 3.61$ & $12.97 \pm 4.03$ \\
\hline 12 & $8.94 \pm 0.73$ & $6.52 \pm 2.10$ & $5.65 \pm 1.52$ & $8.73 \pm 2.33$ & $11.60 \pm 3.97$ \\
\hline 13 & $9.55 \pm 0.50$ & $9.05 \pm 1.01$ & $8.24 \pm 1.79$ & $21.93 \pm 1.27$ & $16.96 \pm 3.99$ \\
\hline 14 & $8.82 \pm 0.71$ & $7.85 \pm 0.93$ & $7.94 \pm 0.90$ & $14.73 \pm 1.74$ & $13.24 \pm 2.30$ \\
\hline 15 & $8.63 \pm 0.70$ & $9.16 \pm 0.88$ & $7.48 \pm 1.56$ & $14.10 \pm 2.58$ & $14.36 \pm 2.63$ \\
\hline 16 & $9.10 \pm 0.44$ & $8.41 \pm 0.95$ & $6.97 \pm 1.36$ & $11.80 \pm 1.98$ & $13.73 \pm 2.11$ \\
\hline 17 & $9.69 \pm 0.33$ & $7.34 \pm 1.62$ & $5.90 \pm 2.08$ & $11.27 \pm 2.46$ & $10.41 \pm 2.10$ \\
\hline 18 & $7.13 \pm 0.88$ & $6.83 \pm 2.12$ & $7.04 \pm 2.28$ & $16.12 \pm 4.96$ & $14.27 \pm 3.71$ \\
\hline 19 & $8.48 \pm 1.25$ & $6.27 \pm 1.66$ & $6.34 \pm 1.36$ & $7.88 \pm 1.12$ & $9.88 \pm 1.77$ \\
\hline 20 & $4.69 \pm 1.03$ & $7.51 \pm 2.06$ & $9.21 \pm 0.86$ & $11.13 \pm 0.66$ & $13.19 \pm 2.09$ \\
\hline 21 & $7.79 \pm 1.50$ & $7.50 \pm 1.74$ & $7.37 \pm 2.32$ & $19.22 \pm 3.74$ & $12.22 \pm 3.80$ \\
\hline 22 & $6.39 \pm 1.78$ & $8.22 \pm 1.86$ & $5.85 \pm 2.31$ & $15.67 \pm 2.92$ & $18.71 \pm 3.84$ \\
\hline 23 & $9.68 \pm 0.38$ & $6.96 \pm 1.65$ & $5.70 \pm 0.58$ & $16.58 \pm 3.72$ & $11.60 \pm 1.99$ \\
\hline 24 & $8.12 \pm 0.98$ & $9.15 \pm 0.74$ & $9.08 \pm 0.63$ & $6.72 \pm 0.66$ & $12.95 \pm 3.09$ \\
\hline 25 & $8.71 \pm 0.75$ & $7.72 \pm 1.23$ & $5.36 \pm 1.40$ & $15.67 \pm 2.86$ & $10.34 \pm 1.97$ \\
\hline 26 & $8.82 \pm 0.88$ & $7.31 \pm 1.71$ & $6.56 \pm 2.09$ & $9.81 \pm 1.75$ & $15.99 \pm 5.43$ \\
\hline 27 & $8.96 \pm 0.57$ & $9.55 \pm 0.49$ & $9.47 \pm 0.40$ & $20.41 \pm 3.01$ & $15.23 \pm 3.70$ \\
\hline 28 & $7.32 \pm 1.29$ & $6.37 \pm 1.44$ & $5.12 \pm 1.81$ & $14.51 \pm 4.03$ & $10.66 \pm 3.03$ \\
\hline 29 & $7.52 \pm 1.47$ & $5.02 \pm 0.65$ & $4.22 \pm 2.06$ & $8.18 \pm 1.91$ & $10.01 \pm 3.28$ \\
\hline 30 & $8.89 \pm 1.16$ & $8.41 \pm 0.30$ & $5.45 \pm 1.76$ & $15.23 \pm 4.52$ & $15.66 \pm 3.84$ \\
\hline
\end{tabular}

Data are expressed as the mean \pm SEM of the total time in seconds spent exploring the objects.

(Winters and Reid, 2010) and extend these results significantly by suggesting a substantial functional reallocation of these cortical areas in response to multisensory object experience.

Consistent with previous permanent lesion results (Winters and Reid, 2010), reversible lesions of PPC in the current study produced significant impairment in the tactile but not the visual SOR task. The tactile SOR deficit was seen with either presample or prechoice lidocaine, indicating that PPC neuronal activity is essential for tactile information processing in either phase of this task. This interpretation is consistent with the fact that PPC receives highly processed somatosensory information (Reep et al., 1994) and has been previously implicated in tactile object recognition (Dijkerman and de Haan, 2007). Accordingly, PPC lidocaine given before the tactile sample phase also disrupted CMOR task performance. A less intuitive finding was the fact that reversible PPC lesions also impaired CMOR when administered before the visual choice phase. However, we have shown previously that lesions disconnecting PPC and PRh selectively disrupt CMOR task performance, suggesting a functional interaction (Winters and Reid, 2010). Given that PRh appears to process predominantly visual information in the basic CMOR task, it follows that this interaction likely occurs during the choice phase when previously encoded tactile object information must be integrated with incoming visual information to facilitate crossmodal recognition.

Particularly striking, given the various effects of PPC lidocaine in CMOR and tactile SOR, is the finding that reversible PPC lesions did not disrupt PE/CMOR task performance under any conditions. Moreover, Fos analyses indicated that multisensory object exposure did not produce significant changes in PPC cellular activation. These results strongly suggest that PPC, which appears to be essential for tactile information processing in the basic CMOR task, is unnecessary for similar task performance when rats have had relatively minimal multisensory experience with the to-be-remembered objects. This indicates that other somatosensory and/or polymodal brain regions are sufficient for tactile processing in the PE/CMOR task. Accordingly, PPC inactivation during or after the multisensory preexposure phase also did not disrupt PE/CMOR task performance. Notably, other, non-PPC, somatosensory areas have been implicated in tactile object processing (Zhou and Fuster, 1997, 2000; Dijkerman and de Haan, 2007; Jadhav and Feldman, 2010). Which of these regions might be involved in $\mathrm{PE} / \mathrm{CMOR}$ performance remains a question for future research.

Reversible lesions of PRh also produced effects in the CMOR and unimodal tasks that are consistent with what we have previously reported after permanent lesions (Winters and Reid, 2010). PRh lidocaine selectively disrupted performance when it was given before visual phases of the tasks (sample and choice phases in visual SOR; choice phase only in CMOR), again highlighting the important role of $\mathrm{PRh}$ in visual object processing (Buckley et al., 2001; Bartko et al., 2007a, 2007b; Bussey and Saksida, 2007; Winters and Reid, 2010; Albasser et al., 2011). In contrast, PRh neuronal activity appears to be essential at every stage of processing in $\mathrm{PE} / \mathrm{CMOR}$, consistent with the hypothesis that $\mathrm{PRh}$ is critically involved in the formation, storage, and utilization of a multisensory object representation resulting from multimodal object preexposure. Furthermore, Fos analyses indicated significant PRh neuronal activation after analogous multimodal object exposure This upregulation was topographically organized, with greatest increases seen in the middle rostral-caudal portion of 


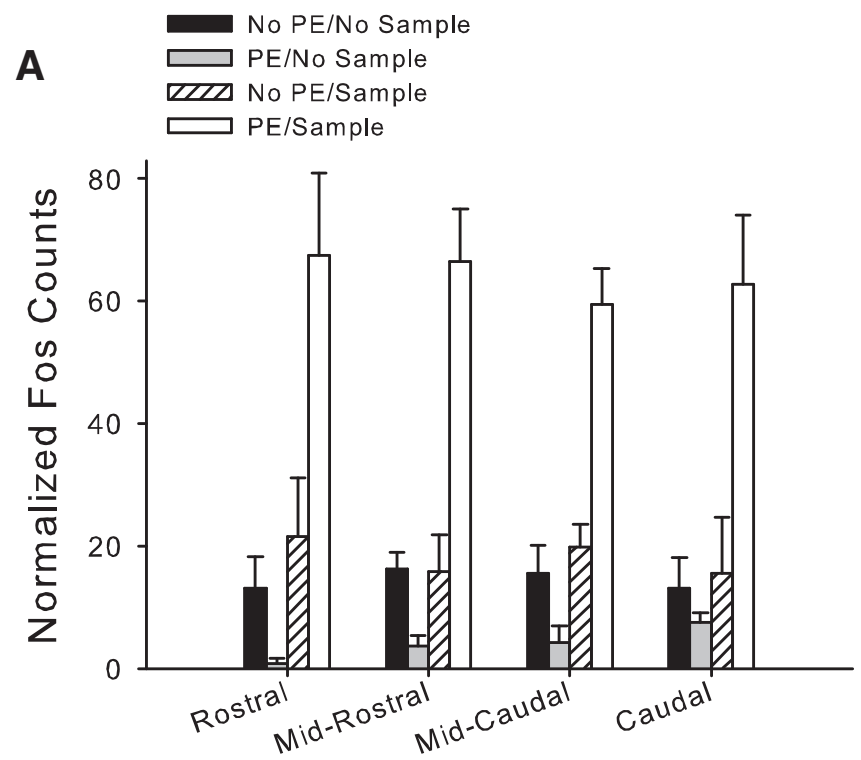

PRh Region (Area 35)

B

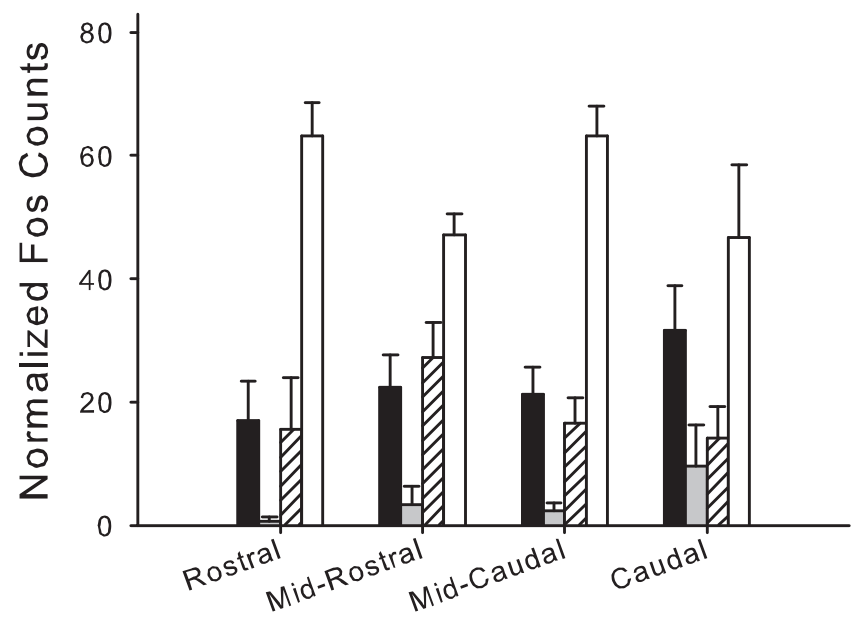

\section{c PRh - No PE/Sample}

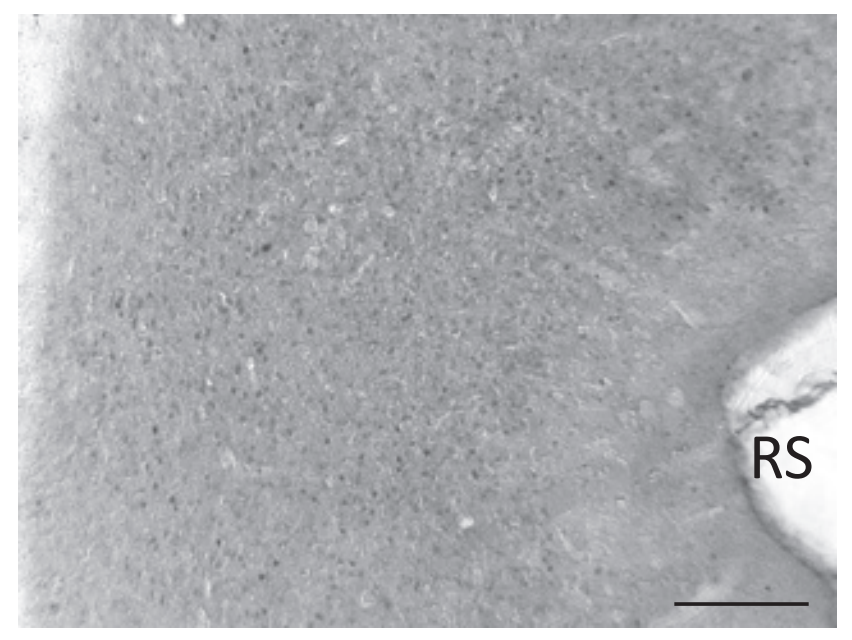

\section{PRh-PE/Sample}

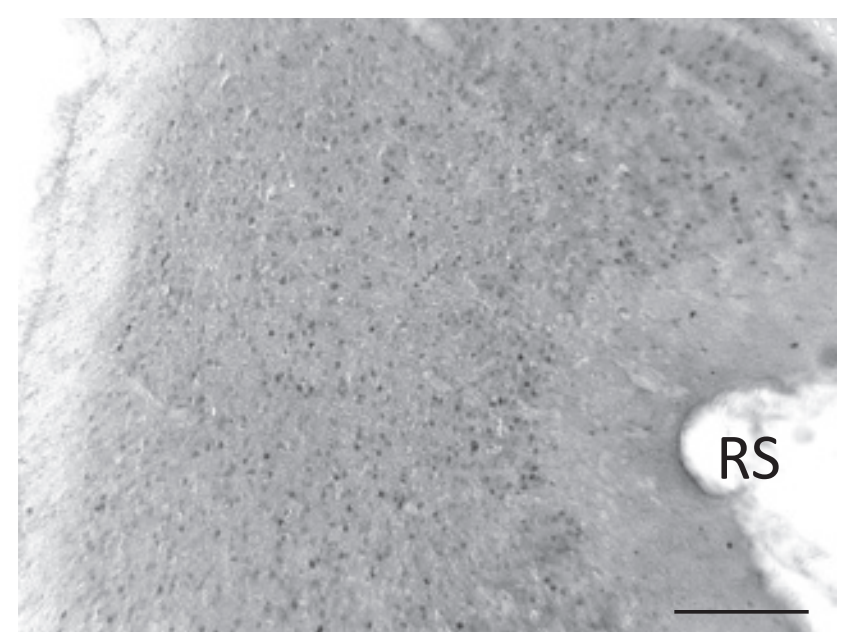

PRh Region (Area 36)

Figure 10. Topographic Fos expression levels in PRh areas $35(\boldsymbol{A})$ and $36(\boldsymbol{B})$ of rats in various combinations of preexposure and sample conditions: no preexposure/no sample $(n=4)$; preexposure/no sample $(n=4)$; no preexposure/sample $(n=4)$; and preexposure/sample $(n=4)$. Rats were killed $1 \mathrm{~h}$ after the second phase (sample or no sample). Rats that experienced multimodal object preexposure followed $24 \mathrm{~h}$ later by a tactile sample phase (reexposure to the same objects) had significantly higher levels of Fos expression throughout all levels of PRh. $\boldsymbol{B}, \boldsymbol{C}$, Microphotographs (10X magnification) of representative slices illustrating Fos-immunoreactivity in PRh ( $\sim 5.2 \mathrm{~mm}$ posterior to bregma) from a rat in no preexposure/sample (C) and preexposure/ sample $(\boldsymbol{D})$ conditions; note the greater number of darkly stained cells in $\boldsymbol{D} .{ }^{* *} p<0.01$; ${ }^{* * *} p<0.001$. RS, Rhinal sulcus. Scale bar, $200 \mu \mathrm{m}$.

area 35 and the most anterior and posterior aspects of area 36. Further research is required to ascertain the significance of this result, but the pattern could reflect inputs from different sensory cortices (Burwell and Amaral, 1998).

Perhaps most intriguing is the finding that PRh inactivation before the tactile sample phase, a manipulation that had no effect in the basic CMOR task, significantly disrupted PE/CMOR performance. This effect was observed, not only with the $3 \mathrm{~h}$ delay typically used to reveal preexposure-induced CMOR facilitation, but also when the delay was reduced to $1 \mathrm{~h}$, a retention interval that does not necessitate object preexposure for successful CMOR task performance. Therefore, the disparity between effects of presample PRh lidocaine in the CMOR and PE/CMOR tasks is not merely a function of different memory demands.
Rather, this pattern of results implies that multimodal object preexposure induces significant changes in the neural circuitry underlying task performance and this functional remapping appears to favor a PRh-dependent strategy even under conditions when such a strategy may not be required; therefore, a PRh-based multisensory object representation might override other potential task solutions when such a representation is available. In agreement with the reversible lesion results, the highest expression of PRh Fos in Experiment 7 was observed in rats that had experienced a tactile sample phase $24 \mathrm{~h}$ after multisensory preexposure to the same objects; PRh activation was substantially higher than all other combinations of preexposure and sample conditions. Interestingly, there were no clear topographic differences within $\mathrm{PRh}$ for this effect. This could reflect widespread 
PRh activation resulting from integration of information from multiple sensory afferents and/or input from polymodal regions (Burwell and Amaral, 1998).

These findings are consistent with the hypothesis that multimodal object preexposure promotes a PRh-dependent multisensory representation that can be activated in full by only partial (i.e., tactile) information in the sample phase. Activation of such a representation during the sample phase would be expected to lead to more robust memory performance than what would be observed when only tactile information is available; this likely explains the fact that multisensory preexposure to the to-beremembered objects greatly extends the retention delay over which the task can be performed (Reid et al., 2012, 2014). Others have suggested, on the basis of numerous behavioral findings from monkeys (Desimone and Gross, 1979; Murray and Mishkin, 1985; Murray et al., 1998; Parker and Gaffan, 1998; Murray and Bussey, 1999; Goulet and Murray, 2001), as well as the established polysensory anatomical connections of PRh (Burwell et al., 1995; Burwell and Amaral, 1998), that this cortical region is crucial for the encoding and storage of multisensory object representations. The combination in the current study of reversible lesions with different CMOR task variants has provided important insight into the nature of $\mathrm{PRh}$ involvement in multisensory object processing, suggesting that its role varies depending on the nature of prior object exposure.

The crossmodal delayed nonmatching to sample task used in monkey studies to implicate PRh in multisensory representation involves an extensive pretraining phase, at the beginning of which monkeys receive multimodal exposure to the training objects over hundreds of trials (i.e., they are allowed to touch and view the objects simultaneously). Importantly, the training objects are typically the same objects that will be used for subsequent crossmodal testing (Murray et al., 1998). Conversely, our original CMOR task never provides the rats the opportunity to see and touch the objects at the same time. We hypothesize that, when the multisensory features of an object are unfamiliar and have yet to be associated, crossmodal recognition requires $\mathrm{PRh}$-mediated visual processing to interact with other modality-specific information in other brain areas (such as PPC); alternatively, when animals have the opportunity to associate the various features of an object, a multisensory object representation is encoded and stored within PRh. Results from early nonhuman primate studies are consistent with the suggestion that the mechanisms of crossmodal recognition for familiar and unfamiliar objects differ (Streicher and Ettlinger, 1987). Moreover, findings from humans suggest that PRh is essential for crossmodal object feature binding and that this role may be linked to the level of meaning with which an object is endowed (Taylor et al., 2006; Holdstock et al., 2009; Taylor et al., 2009). The results of the current study significantly extend these previous findings by clearly demonstrating differential cortical involvement in multisensory object representation depending on the nature and extent of past object experience.

\section{References}

Albasser MM, Poirier GL, Aggleton JP (2010) Qualitatively different modes of perirhinal-hippocampal engagement when rats explore novel vs. familiar objects as revealed by c-Fos imaging. Eur J Neurosci 31:134-147. CrossRef Medline

Albasser MM, Amin E, Iordanova MD, Brown MW, Pearce JM, Aggleton JP (2011) Separate but interacting recognition memory systems for different senses: the role of the rat perirhinal cortex. Learn Mem 18:435-443. CrossRef Medline

Amedi A, von Kriegstein K, van Atteveldt NM, Beauchamp MS, Naumer MJ
(2005) Functional imaging of human crossmodal identification and object recognition. Exp Brain Res 166:559-571. CrossRef Medline

Bartko SJ, Winters BD, Cowell RA, Saksida LM, Bussey TJ (2007a) Perirhinal cortex resolves feature ambiguity in configural object recognition and perceptual oddity tasks. Learn Mem 14:821-832. CrossRef Medline

Bartko SJ, Winters BD, Cowell RA, Saksida LM, Bussey TJ (2007b) Perceptual functions of perirhinal cortex in rats: zero-delay object recognition and simultaneous oddity discriminations. J Neurosci 27:2548-2559. CrossRef Medline

Buckley MJ, Gaffan D (2006) Perirhinal cortical contributions to object perception. Trends Cogn Sci 10:100-107. CrossRef Medline

Buckley MJ, Booth MC, Rolls ET, Gaffan D (2001) Selective perceptual impairments after perirhinal cortex ablation. J Neurosci 21:9824-9836. Medline

Burwell RD (2001) Borders and cytoarchitecture of the perirhinal and postrhinal cortices in the rat. J Comp Neurol 437:17-41. CrossRef Medline

Burwell RD, Amaral DG (1998) Cortical afferents of the perirhinal, postrhinal, and entorhinal cortices of the rat. J Comp Neurol 398:179-205. CrossRef Medline

Burwell RD, Witter MP, Amaral DG (1995) Perirhinal and postrhinal cortices of the rat: a review of the neuroanatomical literature and comparison with findings from the monkey brain. Hippocampus 5:390-408. CrossRef Medline

Bussey TJ, Saksida LM (2007) Memory, perception, and the ventral visualperirhinal-hippocampal stream: thinking outside of the boxes. Hippocampus 17:898-908. CrossRef Medline

Deacon TW, Eichenbaum H, Rosenberg P, Eckmann KW (1983) Afferent connections of the perirhinal cortex in the rat. J Comp Neurol 220: 168-190. CrossRef Medline

Desimone R, Gross CG (1979) Visual areas in the temporal cortex of the macaque. Brain Res 178:363-380. CrossRef Medline

Dijkerman HC, de Haan EH (2007) Somatosensory processes subserving perception and action. Behav Brain Sci 30:189-201, discussion 201-239. Medline

Ennaceur A, Delacour J (1988) A new one-trial test for neurobiological studies of memory in rats. 1: Behavioral data. Behav Brain Res 31:47-59. CrossRef Medline

Forwood SE, Winters BD, Bussey TJ (2005) Hippocampal lesions that abolish spatial maze performance spare object recognition memory at delays of up to 48 hours. Hippocampus 15:347-355. CrossRef Medline

Goulet S, Murray EA (2001) Neural substrates of crossmodal association memory in monkeys: the amygdala versus the anterior rhinal cortex. Behav Neurosci 115:271-284. CrossRef Medline

Holdstock JS, Hocking J, Notley P, Devlin JT, Price CJ (2009) Integrating visual and tactile information in the perirhinal cortex. Cereb Cortex 19: 2993-3000. CrossRef Medline

Jacobs GH, Fenwick JA, Williams GA (2001) Cone-based vision of rats for ultraviolet and visible lights. J Exp Biol 204:2439-2446. Medline

Jadhav SP, Feldman DE (2010) Texture coding in the whisker system. Curr Opin Neurobiol 20:313-318. CrossRef Medline

Lacey S, Campbell C, Sathian K (2007) Vision and touch: multiple or multisensory representations of objects? Perception 36:1513-1521. CrossRef Medline

Lavenex P, Suzuki WA, Amaral DG (2004) Perirhinal and parahippocampal cortices of the macaque monkey: intrinsic projections and interconnections. J Comp Neurol 472:371-394. CrossRef Medline

Málková L, Mishkin M, Bachevalier J (1995) Long-term effects of selective neonatal temporal lobe lesions on learning and memory in monkeys. Behav Neurosci 109:212-226. CrossRef Medline

Murray EA, Bussey TJ (1999) Perceptual-mnemonic functions of the perirhinal cortex. Trends Cogn Sci 3:142-151. CrossRef Medline

Murray EA, Mishkin M (1985) Amygdalectomy impairs crossmodal association in monkeys. Science 228:604-606. CrossRef Medline

Murray EA, Málková L, Goulet S (1998) Cross-modal associations, intramodal associations, and object identification in macaque monkeys. In: Comparative neuropsychology (Milner AD, ed), pp 51-69. Oxford: OUP.

Murray EA, Bussey TJ, Saksida LM (2007) Visual perception and memory: a new view of medial temporal lobe function in primates and rodents $\left({ }^{*}\right)$. Annu Rev Neurosci 30:99-122. CrossRef Medline

Parker A, Gaffan D (1998) Lesions of the primate rhinal cortex cause deficits 
in flavour-visual associative memory. Behav Brain Res 93:99-105. CrossRef Medline

Paxinos G, Watson C (1998) The rat brain in stereotaxic coordinates, Ed 3. London: Academic.

Reep RL, Chandler HC, King V, Corwin JV (1994) Rat posterior parietal cortex: topography of corticocortical and thalamic connections. Exp Brain Res 100:67-84. CrossRef Medline

Reid JM, Jacklin DL, Winters BD (2012) Crossmodal object recognition in rats with and without multimodal object preexposure: no effect of hippocampal lesions. Neurobiol Learn Mem 98:311-319. CrossRef Medline

Reid JM, Jacklin DL, Winters BD (2014) Delineating prefrontal cortex region contributions to crossmodal object recognition in rats. Cereb Cortex 24:2108-2119. CrossRef Medline

Shams L, Seitz AR (2008) Benefits of multisensory learning. Trends Cogn Sci 12:411-417. CrossRef Medline

Streicher M, Ettlinger G (1987) Cross-modal recognition of familiar and unfamiliar objects by the monkey: the effects of ablation of polysensory neocortex or of the amygdaloid complex. Behav Brain Res 23:95-107. CrossRef Medline

Suzuki WA, Amaral DG (1994) Perirhinal and parahippocampal cortices of the macaque monkey: cortical afferents. J Comp Neurol 350:497-533. CrossRef Medline

Taylor KI, Moss HE, Stamatakis EA, Tyler LK (2006) Binding crossmodal object features in perirhinal cortex. Proc Natl Acad Sci U S A 103:82398244. CrossRef Medline

Taylor KI, Stamatakis EA, Tyler LK (2009) Crossmodal integration of object features: voxel-based correlations in brain-damaged patients. Brain 132: 671-683. CrossRef Medline

Unal G, Apergis-Schoute J, Paré D (2012) Associative properties of the perirhinal network. Cereb Cortex 22:1318-1332. CrossRef Medline

Wan H, Aggleton JP, Brown MW (1999) Different contributions of the hippocampus and perirhinal cortex to recognition memory. J Neurosci 19: 1142-1148. Medline

Winters BD, Bussey TJ (2005) Transient inactivation of perirhinal cortex disrupts encoding, retrieval, and consolidation of object recognition memory. J Neurosci 25:52-61. CrossRef Medline

Winters BD, Reid JM (2010) A distributed cortical representation underlies crossmodal object recognition in rats. J Neurosci 30:6253-6261. CrossRef Medline

Winters BD, Forwood SE, Cowell RA, Saksida LM, Bussey TJ (2004) Double dissociation between the effects of peri-postrhinal cortex and hippocampal lesions on tests of object recognition and spatial memory: heterogeneity of function within the temporal lobe. J Neurosci 24:5901-5908. CrossRef Medline

Winters BD, Saksida LM, Bussey TJ (2008) Object recognition memory: neurobiological mechanisms of encoding, consolidation and retrieval. Neurosci Biobehav Rev 32:1055-1070. CrossRef Medline

Zhou YD, Fuster JM (1997) Neuronal activity of somatosensory cortex in a cross-modal (visuo-haptic) memory task. Exp Brain Res 116:551-555. CrossRef Medline

Zhou YD, Fuster JM (2000) Visuo-tactile cross-modal associations in cortical somatosensory cells. Proc Natl Acad Sci U S A 97:9777-9782. CrossRef Medline 